\title{
Reliability Testing and Stress Measurement of QFN Packages Encapsulated by an Open-ended Microwave Curing System
}

\begin{tabular}{|r|l|}
\hline Journal: & Transactions on Components, Packaging and Manufacturing Technology \\
\hline Manuscript ID & TCPMT-2018-141.R1 \\
\hline Manuscript topic: & ELECTRONICS MANUFACTURING \\
\hline Date Submitted by the Author: & O6-Jul-2018 \\
\hline Complete List of Authors: & $\begin{array}{l}\text { Adamietz, Raphael; Fraunhofer Institut für Produktionstechnik und } \\
\text { Automatisierung, Ultra-Clean Technology and Micro Manufacturing } \\
\text { Desmulliez, Marc; Heriot-Watt University, Engineering \& Physical Sciences } \\
\text { Pavuluri, Sumanth; Heriot Watt University, EECE, EPS } \\
\text { Tilford, Tim; University of Greenwich, Computing and Mathematical } \\
\text { Sciences } \\
\text { Bailey, Chris; University of Greenwich, Computational Mechanics and } \\
\text { Reliability } \\
\text { Warmuth, Jens; Fraunhofer Institute for Integrated Circuits IIS, } \\
\text { Engineering of Adaptive Systems EAS } \\
\text { Schreier-Alt, Thomas; Hochschule Ravensburg-Weingarten, Fakultät } \\
\text { Maschinenbau }\end{array}$ \\
\hline Keywords: & \begin{tabular}{l} 
Stress measurement, Microwave curing, Thermal cycling test \\
\hline
\end{tabular} \\
\hline
\end{tabular}




\title{
Reliability Testing and Stress Measurement of QFN Packages Encapsulated by an Open-ended Microwave Curing System
}

\author{
Raphael Adamietz, Marc P.Y. Desmulliez, Senior Member IEEE, Sumanth K. Pavuluri, Tim Tilford, \\ Chris Bailey, Senior Member IEEE, Thomas Schreier-Alt and Jens Warmuth
}

\begin{abstract}
In this paper, the influence of microwave curing on the reliability of a representative electronic package is examined by reliability testing and measurement of residual stresses. A LM358 voltage regulator die was mounted to an open Quad Flat No-leads package $(Q F N)$ for reliability testing. For the stress measurement, a specifically designed stress measurement die was mounted to the QFN package. The chips were encapsulated with_Hysol EO1080 thermosetting polymer material. Curing was performed using an open-ended microwave oven system equipped with in situ temperature control. Three different temperature profiles for microwave curing were selected according to the requested degree of cure and chemical composition of the cured material. A convection cure profile was selected for the control group samples. Thermal cycling and HAST tests were performed on a total number of 80 chips. 95 QFN packages with stress measurement chips were also manufactured. Increased lifetime expectancy of the microwave cured packaged chips was experimentally demonstrated and measured between $62 \%$ to $149 \%$ increased lifetime expectancy after Temperature Cycling Test (TCT), and between $63 \%$ and $331 \%$ after highly Accelerated Ageing Test (HAST) and TCT compared to conventionally cured packages. Analysis of specifically designed stress test chips showed significantly lower residual stresses ranging from $26 \mathrm{MPa}$ to 58.3 MPa within the microwave cured packages compared to conventionally cured packaged chips which displayed residual stresses ranging from $54 \mathrm{MPa}$ to $80.5 \mathrm{MPa}$. This article therefore provides additional confidence in the industrial relevance of the microwave curing system and its advantages compared to traditional convection oven systems.
\end{abstract}

Index Terms - encapsulation, microwave curing, microelectronics packaging, reliability testing, open-ended oven, residual stress, accelerated stress test, convection oven.

R. Adamietz is with the Fraunhofer-Institute Manufacturing Engineering and Automation IPA, Nobelstr. 12, 70569 Stuttgart, Germany (email: raphael.adamietz@ipa.fraunhofer.de)

T. Tilford and C. Bailey are with the Department of Mathematical Sciences, University of Greenwich, London SE10 9LS, UK (email: t.tilford@gre.ac.uk, c.bailey@gre.ac.uk)

\section{INTRODUCTION}

E ncapsulant materials are used to protect semiconductor devices and interconnects from damaging external environments where moisture and radiation can cause early failure of the package. Encapsulants and polymer underfill materials can also be used to reduce the CTE mismatch between interconnects (wirebonds, solders) when subjected to thermal cycling loads. For example, thermally induced failures observed in flip-chip solder bumps is due to the difference in magnitude of the thermal expansion coefficients between the chip and the substrate, which can cause significant shear strain on the interconnects, ultimately resulting in fatigue cracking and electrical failure [1]. The residual stress in the polymer materials resulting from the curing process is important to control, as these stresses can act as precursors to failure. Uniformly heating and curing the polymer materials through microwave energy opens up the possibility of achieving this. It also provides the opportunity to decrease the time for applying and curing these materials compared to conventional approaches.

The curing of these thermosetting polymer materials, dispensed in a liquid or semi-liquid form, is conventionally carried out in diffusion or laminar flow-based convection ovens, whereby samples are heated indirectly $[2,3]$. In previous studies, the successful design, manufacture and characterization of a novel open-ended microwave oven system was demonstrated for the curing of polymer materials used in the encapsulation of microelectronic chips [4-6]. This paper builds upon that work, by demonstrating the benefits for reliability of these packages when the polymer materials are cured by microwave energy. Microwave radiation heats in a volumetric manner resulting in a less severe temperature gradient within the material,

S.K. Pavuluri and M.P.Y. Desmulliez are with the Research Institute of Sensors, Signals \& Systems, Heriot-Watt University, EH14 4AS, Scotland, UK (email: sumanth_kumar.pavuluri@hw.ac.uk, m.desmulliez@hw.ac.uk).

T. Schreier-Alt is with the Hochschule Ravensburg-Weingarten,

Leibnizstraße 9, 88250 Weingarten, Germany (email:schreith@hs-weingarten.de)

J. Warmuth is with the Fraunhofer-Institute for Integrated Circuits IIS Engineering of Adaptive Systems EAS, Zeunerstr. 38, 01069 Dresden, Germany (email: jens.warmuth@eas.iis.fraunhofer.de) 
potentially leading to reduced internal residual stresses. Consequently, higher reliability and longer lifetime would be expected for microwave cured packages and assemblies.

After the successful demonstration that pulsed microwave curing had no effect on the normal operation of integrated circuits (IC's) [4], the key question was to verify first whether microwave curing did change the chemical composition of the encapsulant materials beyond these modifications incurred by thermal heating. Enthalpy relaxation measurements performed on conventional and microwave cured samples were reported by some of the authors of this article [5, 6]. Post cure properties of the materials were investigated using differential scanning calorimetry (DSC) and Fourier transformed infrared spectroscopy (FTIR) analysis [6]. The use of microwave energy to cure epoxy resins filled with silica-based filler and carbon additives were demonstrated not to affect the glass transition temperature, $T_{g}$, and the chemical properties of the resulting epoxy resin. The microwave samples tested had a slightly higher degree of cross-linking and the long-term ageing properties of the material were slightly improved. The lack of change in thermal and chemical properties combined with the increase in curing rate (and thus decrease in cure time) makes microwave heating an advantageous method for the curing of epoxy resins used for encapsulation of IC's. The study enhanced the understanding of microwave effects on the chemical composition and ageing behavior for microwavebased processing of polymer materials but the reliability and stress analysis of the IC's cured with microwave curing compared with conventional heating were not carried out. The present paper complements the previous work implemented in [5] and [6]. After a brief description of the microwave oven system in Section II, the reliability tests of microwave and conventional cured QFN IC packages, are presented in section III. These include the preparation of test samples, the temperature cycle testing (TCT), highly accelerated stress test (HAST) and the determination of the reliability for four different temperature cure profiles. Conclusions on the benefits of microwave curing with regard of reliability and stress analysis of the IC's are finally discussed in Section IV.

\section{INTEGRATED MicrowaVE SYSTEM OvEN}

\section{A. Open-Ended Microwave Applicator}

Microwave heating was implemented using a novel open-ended cavity oven. The schematic of the microwave applicator (head) is shown in Fig. 1 [7]. The oven applicator consists of a rectangular metal waveguide cavity, with inner dimensions of $20 \times 20 \times 100 \mathrm{~mm}^{3}$, which is partially filled with the low loss dielectric material polytetrafluoroethylene (PTFE), and a ceramic insert, another low loss dielectric material, to maximize the energy density at the ceramic-air interface.

Electromagnetic energy travels through a waveguide at frequencies above a critical 'cut-off' frequency, which is a function of the cavity dimensions and the material it contains. As the cavity contains two materials (air and PTFE/ceramic), the cut-off frequency changes at the dielectric-air interface. The system is designed to operate at frequencies above the cut-off frequency of the ceramic section but below the cut-off frequency of the air-filled load section. A resonant field pattern is therefore created within the dielectric portion of the cavity. The fields in the load (air) section cannot propagate and decrease exponentially in magnitude away from the ceramic/air interface.

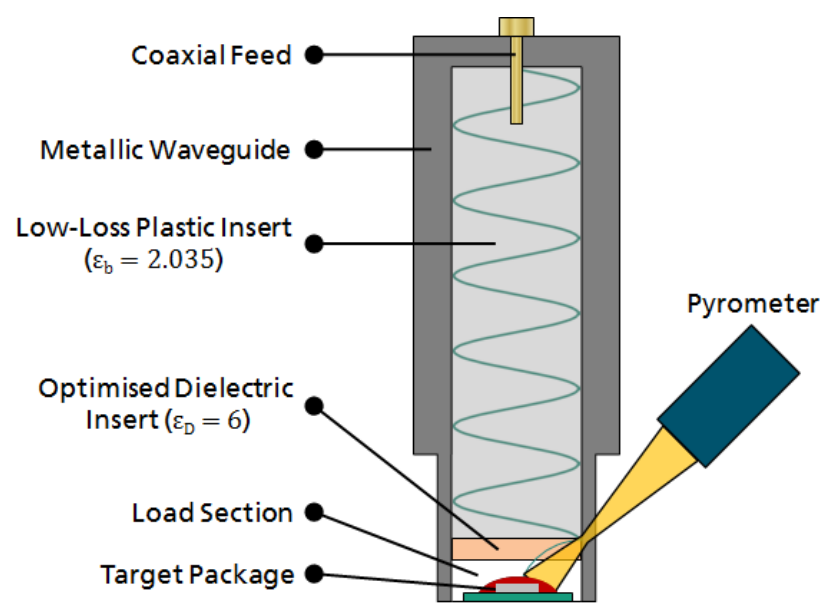

Fig. 1. Open-Ended Microwave Oven

Materials, such as thermosetting polymers, placed within the load section are exposed to these evanescent electro-magnetic fields which induce heating at a rate dependent upon the field strength, the material properties of the load and the frequency of excitation [6]. Heating patterns generated in the load are therefore dependent upon the electric field distribution, which, in turn, depends on the operating frequency. The system can be operated at a large number of discrete harmonic resonant frequencies, each resulting in a differing modal structure within the dielectric. The heating pattern within the load can therefore be controlled through the choice of operating frequency. The field in the heating chamber can be enhanced significantly by the integration of an optimized dielectric material, as depicted in Fig. 1 [5].

\section{B. Control System}

Fig. 2 shows the functional block diagram of the microwave oven curing system. The open-ended oven is driven by a HP $8350 \mathrm{~B}$ sweep oscillator which is a microwave signal generator, coupled to an X-band 44-dBm traveling wave tube (TWT) amplifier. Directional couplers monitor and measure the forward and backward power flows, enabling thereby the measurement of the net power flow into the microwave oven. The oven is intended to operate within a restricted few frequency modes to reduce the complexity of the wide-band amplifier. The necessary standard radio frequency (RF) components are complemented by a miniature pyrometer (Sensortherm CT84-00). Controlled by a computer, this configuration enables the automatic feedback necessary to maintain the temperature within a given profile by switching on/off the HP 8350B sweep oscillator.

A Labview ${ }^{\mathrm{TM}}$ program [8] has been developed to drive the oven to achieve maximum electromagnetic field energy in the heating region. This control system monitors the heating temperature and allows the setup and control of temperature ramp-up and ramp-down rates, the holding of temperatures and the curing time intervals. 


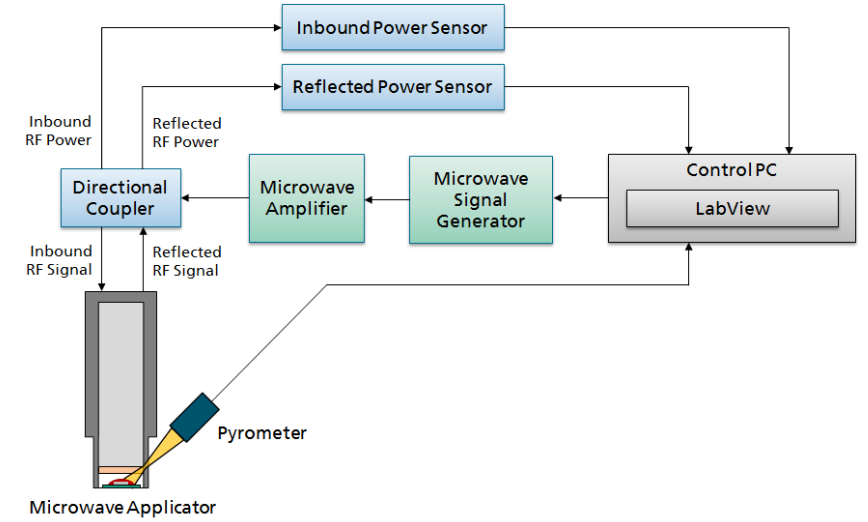

Fig. 2. Functional block diagram of the microwave curing system

Fig. 3 shows the open-ended oven with the integrated miniature infrared pyrometer. The temperature inside the cured material is slightly higher than the measured temperature in the openended oven. This is due to the volumetric heating capability of the microwaves and the limitation of the pyrometer in measuring only surface temperature. The digital signals from the pyrometer and the applicator head are interfaced to the computer via an RS-232 communication interface in order to $\log$ the temperature output. The temperature and the power were recorded during the process analogue to the experiments reported by Pavuluri et al. [4].

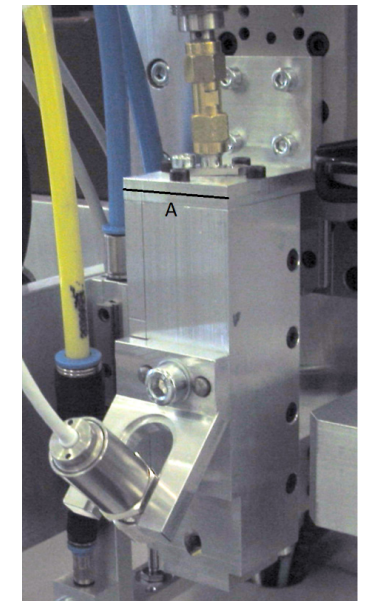

Fig. 3. Photograph of the open-ended microwave oven with integrated pyrometer (front). The scale bar A is $21 \mathrm{~mm}$.

\section{RELIABILITy TESTS}

A commercial LM2940C $12 \mathrm{~V}$ voltage regulator, assembled in a $5 \times 5 \times 0.9 \mathrm{~mm}^{3}$ QFN package, was chosen as the test vehicle. The electrically conductive adhesive, Henkel Hysol CE3103WLV, was used as the die-bonding paste. The voltage regulator die has six bond pads, which were connected to the package using gold wires of diameter of $25 \mu \mathrm{m}$ diameter. A dam, made out of an epoxy-based material, was already applied by the package manufacturer. The chip, in this state, is ready for a cavity-fill encapsulation process.

Eighty samples were produced by dispensing a defined portion of Henkel Hysol EO1080 using a time-pressure dispenser into the cavity. The dispenser parameters have been determined empirically, resulting in a dispensed mass of $21 \mathrm{mg}$ with a tolerance of $\pm 10 \%$. The samples were processed with different profiles, as presented in Table I. All 80 chips were tested for functionality before and directly after cure. No defective chip was recorded.

TABLE I

SAMPLES FOR RELIABILITY TESTS

\begin{tabular}{cccccc}
\hline \hline $\begin{array}{c}\text { Profile } \\
\text { No. }\end{array}$ & Cure Type & $\begin{array}{c}\text { No. of } \\
\text { Samples }\end{array}$ & Ramp Rate & $\begin{array}{c}\text { Set } \\
\text { Temp. }\end{array}$ & $\begin{array}{c}\text { Hold } \\
\text { Time }\end{array}$ \\
\hline 1 & Microwave & 20 & $1.66^{\circ} \mathrm{C} / \mathrm{s}$ & $150^{\circ} \mathrm{C}$ & $100 \mathrm{~s}$ \\
2 & Microwave & 20 & $0.65^{\circ} \mathrm{C} / \mathrm{s}$ & $150^{\circ} \mathrm{C}$ & $180 \mathrm{~s}$ \\
3 & Microwave & 20 & $0.4^{\circ} \mathrm{C} / \mathrm{s}$ & $150^{\circ} \mathrm{C}$ & $669 \mathrm{~s}$ \\
4 & Convection & 20 & - & $150^{\circ} \mathrm{C}$ & $1200 \mathrm{~s}$ \\
\hline \hline
\end{tabular}

Ten chips were assembled for each profile, resulting in a first set of 40 samples subjected to a temperature cycling test (TCT) based on the JEDEC JESD22-A104 standard [9]. Temperatures were cycled between $-55^{\circ} \mathrm{C}$ and $150^{\circ} \mathrm{C}$ with dwell times of 600 s. A total of 1,000 cycles were conducted. Intermediate functionality measurements were carried out every 50 cycles. Failure numbers as a function of the number of cycles for each profile are presented in Fig. 4. A total of 19 samples failed after completion of the 1,000 cycles. Two failure modes were identified: open circuit and intermittent failures. Some of the components showing intermittent failures recovered temporarily after further thermal cycling before they completely failed. Visual inspection was performed on the failed components where identifiable mechanical defects were evident. The mechanical stresses induced by the temperature cycles lead in two cases to propagation of cracks in the plastic package until eventually the electrical connection was broken. One specimen showed a pore of vaporized material, which was likely caused by a void inside the encapsulant. In all nonfunctional packages the cause of failure was a discontinued electrical contact.
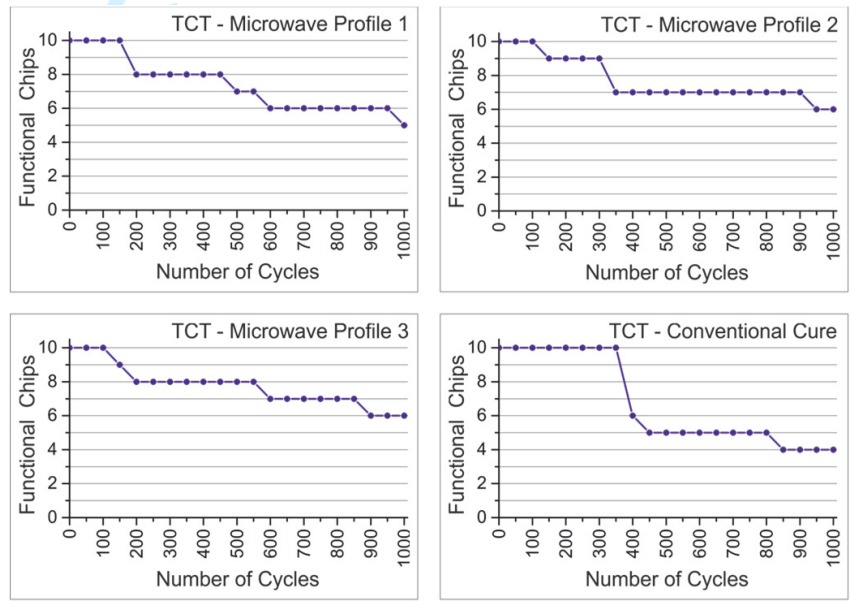

Fig. 4. Failures of the packaged chips during the temperature cycling test

The remaining 40 samples, 10 chips per profile, were exposed to a highly accelerated stress test (HAST), according to the JESD22-A110 standard [10]. In this test, samples were exposed for 96 hours to a temperature of $130^{\circ} \mathrm{C}$ and a relative humidity of $85 \%$. All chips were tested before and after HAST. The chips were then subjected to a TCT, with $\mathrm{T}$ ranging from $-55^{\circ} \mathrm{C}$ to $150^{\circ} \mathrm{C}, 600 \mathrm{~s}$ dwell time, 1,000 cycles, with intermediate testing 
every 50 cycles. All chips successfully passed the HAST test. After completion of the TCT however, a total of 18 chips failed. The numbers of functional chips as a function of the number of cycles are presented in Fig. 5 for all four curing profiles.
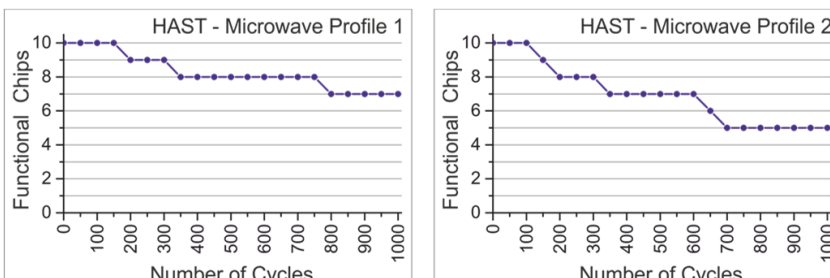
Number of Cycles
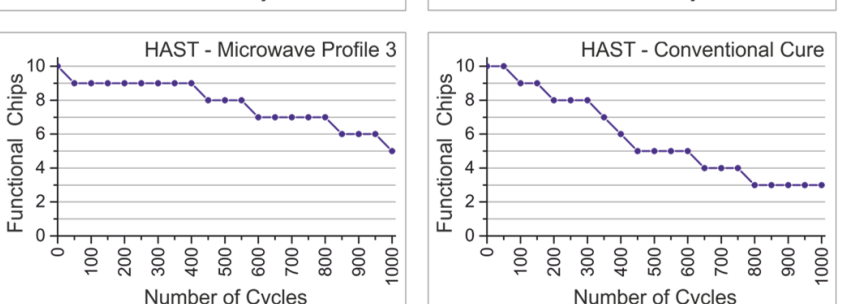

Fig. 5. Failures of the packaged chips during the temperature cycling test (TCT) after exposure to HAST.

Based on the failure moments of the single failure mode, twoparameter Weibull functions were approximated using the software package Reliasoft Weibull++ [11]. The resulting function properties are presented in Table II. Additionally plots of the Weibull functions are presented in the supplementary materials to this paper. All microwave cured profiles show higher median values, $\mu$, and characteristic lifetimes, $\eta$, compared to the conventionally cured samples (Profile 4). The characteristic lifetimes in TCT improved between $62 \%$ and $149 \%$ compared the control group. The chips exposed to TCT after HAST exhibited an increase between $63 \%$ and $331 \%$.

TABLE II

CALCUlATED LIFE-TIMES BASED ON WEIBULL APPROXIMATION

\begin{tabular}{|c|c|c|c|c|}
\hline & $\begin{array}{c}\text { Profile } \\
1\end{array}$ & Profile 2 & Profile 3 & Profile 4 \\
\hline \multicolumn{5}{|l|}{ TCT } \\
\hline$\beta$ & 1.09 & 0.98 & 0.87 & 1.77 \\
\hline$\eta$ & 1467.58 & 1858.14 & 2260.74 & 907.68 \\
\hline$\mu$ & 1421.75 & 1874.16 & 2425.77 & 808.28 \\
\hline$\sigma^{2}$ & $1.68 \cdot 10^{6}$ & $3.65 \cdot 10^{6}$ & $7.83 \cdot 10^{6}$ & $2.21 \cdot 10^{5}$ \\
\hline \multicolumn{5}{|l|}{ TCT after HAST } \\
\hline$\beta$ & 1.02 & 1.16 & 0.66 & 1.31 \\
\hline$\eta$ & 2366.50 & 1239.87 & 3291.67 & 762.88 \\
\hline$\mu$ & 2346.87 & 1176.25 & 1313.15 & 702.90 \\
\hline$\sigma^{2}$ & $5.29 \cdot 10^{6}$ & $1.02 \cdot 10^{6}$ & $1.11 \cdot 10^{6}$ & $2.96 \cdot 10^{5}$ \\
\hline \multicolumn{5}{|l|}{ Increase of $\eta$} \\
\hline TCT & $62 \%$ & $105 \%$ & $149 \%$ & - \\
\hline TCT after HAST & $210 \%$ & $63 \%$ & $331 \%$ & - \\
\hline Survival Means Test & $\mu_{1} / \mu_{4}$ & $\mu_{2} / \mu_{4}$ & $\mu_{3} / \mu_{4}$ & \\
\hline TCT & $\mathrm{p}=0.22$ & $\mathrm{p}=0.07$ & $p=0.02$ & - \\
\hline TCT after HAST & $\mathrm{p}<0.01$ & $\mathrm{p}=0.26$ & $\mathrm{p}=0.17$ & - \\
\hline Effect size d & $\mathrm{d}_{1} / \mathrm{d}_{4}$ & $\mathrm{~d}_{1} / \mathrm{d}_{4}$ & $\mathrm{~d}_{1} / \mathrm{d}_{4}$ & \\
\hline TCT & 0.7 & 0.8 & 0.8 & - \\
\hline TCT after HAST & 1.0 & 0.7 & 0.6 & - \\
\hline
\end{tabular}

A survival means test was performed between each of the groups which were cured using microwave energy and the control group [12]. From the chips exposed to 'TCT' alone, only profile $3(\mathrm{p}=0.02)$ shows statistically significant differences in mean life time with a $90 \%$ confidence interval and a significance threshold of $p<0.1$. From the specimen subjected to the test 'TCT after HAST', profile $1(\mathrm{p}<0.01)$ showed a statistically significant difference compared to the control group. Although the sample size was relatively small, statistically significant improvements of lifetime could be observed due to the magnitude of the effect. To assess the size of the effect, Cohen's d was calculated for all microwave profiles. The values range between 0.6 and 1.0, which corresponds to a 'large' effect in all cases [13].

With respect to the Temperature Cycling Test alone, longer cure cycles with lower ramp rates are suspected to improve the lifetime of the packaged chips as observed from the results obtained for profile 1 to profile 3 . Results from multi-physics modelling [14] indicate that longer cure cycles and lower ramp rates lead to less residual stress, which is a significant factor of package lifetime, which principally supports the hypothesis.

The results from 'TCT after HAST' show a slightly different picture. The high lifetime observed in profile 1 is particularly remarkable. A possible explanation could be that the encapsulant was not fully cured and was eventually cured during HAST. As lower temperatures are used during HAST, this could possibly lead to reduced residual stresses, which would in turn likely improve the lifetime of the packaged device.

\section{In-Package Stress Measurement}

Results from reliability testing demonstrated a significantly improved reliability of microwave-cured packages compared to their conventionally cured counterparts. A potential explanation for this improvement could be due to the reduction of residual stresses caused by microwave curing compared to those of convection oven curing. As microwave curing provides volumetric heating, it is suspected to provide a more uniform curing process, with lower residual stresses compared to convection heating. This section of the article attempts to verify experimentally whether this is the case.

Many versions of stress-measurement chips have been developed within the last decade in order to measure residual stresses during curing and subsequently optimise the heating process [15-21]. The chip used in this study was developed by Robert Bosch $\mathrm{GmbH}$ as part of the BMBF-funded project iForceSens [19]. A calibrated test chip and an ASIC control unit form the main components of the system [22]. The test chip itself was fabricated using CMOS technology and contains orthogonal current mirrors sensitive to stress [19]. For this chip, an external mechanical load causes an asymmetry of the current mirrors [20]. The change in the drain current within these orthogonal Si-MOSFETs is described by the theory of piezoresistivity as applied on silicon:

$$
R_{i, j}(\sigma)=R_{0} \cdot\left(1+\sum_{k, l} \pi_{i, j, k, l} \cdot \sigma_{k, l}\right)
$$

where $\sigma_{k, l}$ is one of the stress tensor components, $\pi$ is the fourth order piezoresistive tensor and $R$ is the resistance [21]. The piezoresistive tensors can be determined by a series of fourpoint bending tests on silicon strips at defined orientations and at various temperatures [19]. 
The stress sensor ASIC is structured with an array of orthogonally oriented nMOS and pMOS structures. The nMOS transistor channels are oriented along the [010] and [100] silicon crystal directions and are used to calculate the in-plane shear stress $\tau_{x y}$ as described by Equation (2) $[22,23]$. The pMOS transistor channels are aligned in the [-110] and [110] directions and are used to determine the in-plane normal stress $\sigma_{x x}-\sigma_{y y}$ as described by Equation (3) [22].

$$
\begin{gathered}
\tau_{x y} \approx \frac{-1}{\pi_{11}^{(n)}-\pi_{12}^{(n)}} \frac{I_{\text {out }}-I_{\text {in }}}{I_{\text {out }}+I_{\text {in }}} \\
\sigma_{x x}-\sigma_{y y} \approx \frac{2}{\pi_{44}^{(p)}} \frac{I_{\text {out }}-I_{\text {in }}}{I_{\text {out }}+I_{\text {in }}} \\
\sigma_{x x}+\sigma_{y y} \approx \frac{2}{\pi_{11}^{(n)}+\pi_{12}^{(n)}}\left(1-\frac{I_{\text {in }}+I_{\text {out }}}{2 I_{0}}-\pi_{12}^{(n)} \sigma_{z z}\right)
\end{gathered}
$$

By determination of the sum of the in-plane normal stresses as described by Equation (4), it becomes possible to calculate the normal in-plane stress components $\sigma_{x x}$ and $\sigma_{y y}$ [22]. The calculation of the components can be performed with an accuracy of $13 \%$, while shear stress and normal stress differences can be calculated with an accuracy down to $4.5 \%$ and $1.2 \%$, respectively [19]. These accuracies apply as long as the stress component $\sigma_{z z}$ normal to the chip surface is negligible $(<10 \mathrm{MPa})$ or is known and the temperature is measured correctly [20]. The measurement accuracy further depends on the integration time during measurement [21].

Different array configurations of this particular stress chip are available [22]. A version with dimensions $1.13 \times 1.11 \mathrm{~mm}^{2}$ was chosen here as the dimensions of the chip are comparable to those of the previously used voltage regulator die, enabling us thereby to use the same QFN packages as in the reliability tests. Pictures of the die and the open QFN package are shown in Fig. 6. A total of 104 stress-measurement dies were die-bonded to the QFN packages using the Henkel CE3103WLV isotropic conductive adhesive. The four die contacts were wire bonded to the chip casing using $25 \mu \mathrm{m}$ gold wire. 9 chips were sacrificed for the determination of the appropriate applicable process parameters, particularly for the dispensing process.

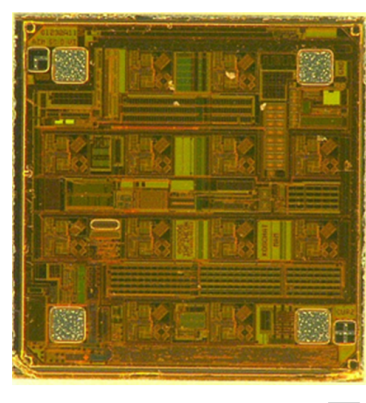

Bare Die

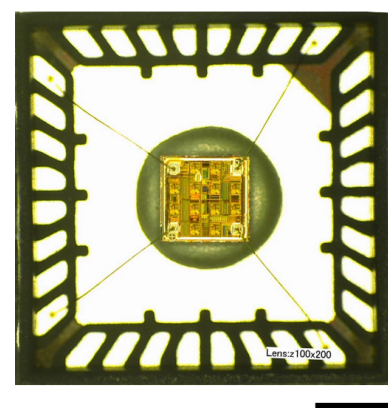

Die in QFN Package
Fig. 6. Stress measurement chip as bare die and in QFN package. The scale bar on the left is $100 \mu \mathrm{m}$, the scale bar on the right is $1 \mathrm{~mm}$.

The initial stresses on the open packages were measured as a zero-level reference. A total of 95 packages were encapsulated with the same four curing profiles as used for the reliability tests. 25 samples were prepared the three microwave curing profiles, and 20 packages were cured using convection heating. A total of four chips were discarded as these had either visible voids or strongly irregular surfaces (three from Profile 1, and one from Profile 2). Table III shows an overview of the prepared samples and the cure profiles applied.

TABLE III

SAMPLES For IN-PACKage StRESS MEASUREMENT TESTS

\begin{tabular}{cccccc}
\hline \hline $\begin{array}{c}\text { Profile } \\
\text { No. }\end{array}$ & Cure Type & $\begin{array}{c}\text { No. of } \\
\text { Samples }\end{array}$ & Ramp Rate & $\begin{array}{c}\text { Set } \\
\text { Temp. }\end{array}$ & $\begin{array}{c}\text { Hold } \\
\text { Time }\end{array}$ \\
\hline 1 & Microwave & 22 & $1.66^{\circ} \mathrm{C} / \mathrm{s}$ & $150^{\circ} \mathrm{C}$ & $100 \mathrm{~s}$ \\
2 & Microwave & 24 & $0.65^{\circ} \mathrm{C} / \mathrm{s}$ & $150^{\circ} \mathrm{C}$ & $180 \mathrm{~s}$ \\
3 & Microwave & 25 & $0.4^{\circ} \mathrm{C} / \mathrm{s}$ & $150^{\circ} \mathrm{C}$ & $669 \mathrm{~s}$ \\
4 & Convection & 20 & - & $150^{\circ} \mathrm{C}$ & $1,200 \mathrm{~s}$ \\
\hline \hline
\end{tabular}

After the curing cycle, the chips were allowed to passively cool down to room temperature. Stress was measured for each of the encapsulated chips the next day after the curing procedure. One stress chip from Profile 2 was not readable and was discarded. All other samples were readable. The distributions of the inplane normal stresses $\sigma_{x x}$ and $\sigma_{y y}$, as well as the distributions of shear stresses $\tau_{x y}$ were determined for each chip, allowing thereby the determination of the whole plane stress tensor $\sigma$. Based on the individual components of the stress tensor, an equivalent stress can be calculated - facilitating a comparison of the stress between different chips. Different hypotheses for the calculation of the equivalent stress were considered. The previously identified failure mechanisms are the cracking of polymer structures and subsequent breaking of wire bonds. The silicon die itself is not affected; therefore, the relevant materials for the equivalent stress are the surrounding polymers and the metallic wires. Both of these materials can be regarded as ductile [24]. For these type of materials, the equivalent stress $\sigma_{v}$ can be calculated according to the von Mises formula for equivalent stress [25]. The planar distributions of the von Mises equivalent stress $\sigma_{v}$ have been calculated for each chip. The resulting equivalent stress for the four profiles is depicted in the figures ranging from Fig. 7 to Fig. 10. The pictures showing the equivalent stress on the left show the mean values for each profile, by calculating the arithmetic mean for each data point (more details in the online supplements to this paper). The corresponding variance is presented right next to the distribution of the mean equivalent stress. Figures with the individual stress components $\sigma_{\mathrm{xx}}, \sigma_{\mathrm{yy}}$ and $\tau_{\mathrm{xy}}$, as well as the difference in planar stress $\sigma_{\mathrm{xx}}-\sigma_{\mathrm{yy}}$ are provided in the supplementary materials to this paper.

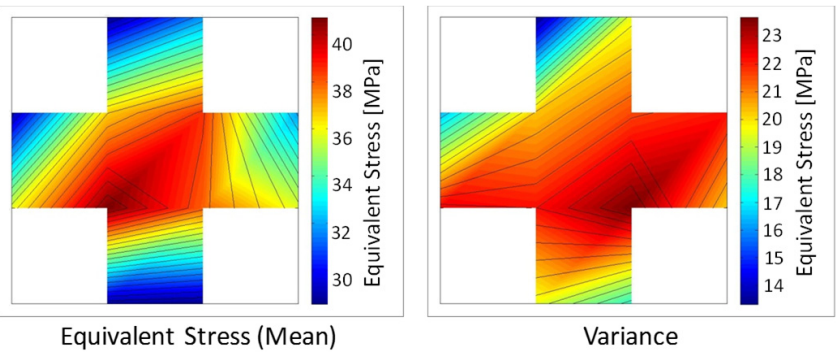

Fig. 7. Profile 1: Equivalent stress (left) and variance (right) 


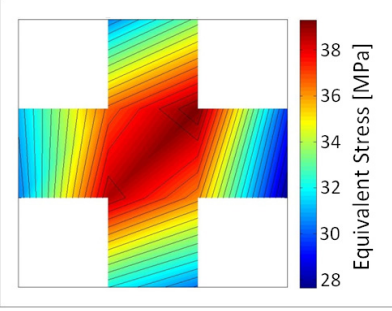

Equivalent Stress (Mean)

Fig. 8. Profile 2: Equivalent stress (left) and variance (right)

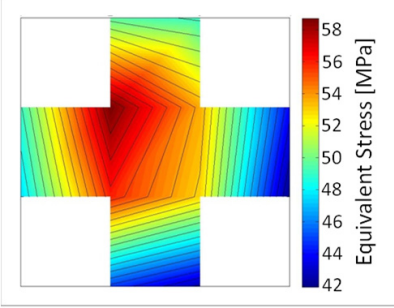

Equivalent Stress (Mean)

Fig. 9. Profile 3: Equivalent stress (left) and variance (right)

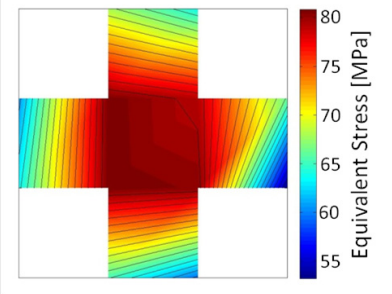

Equivalent Stress (Mean)

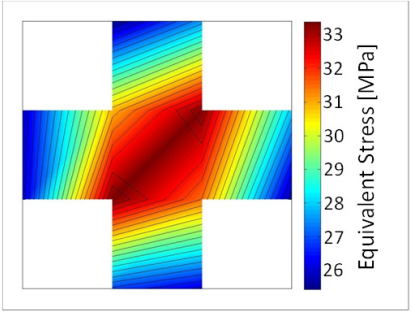

Variance

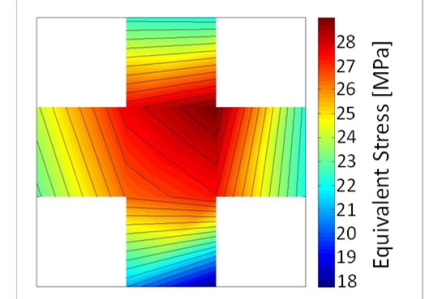

Variance

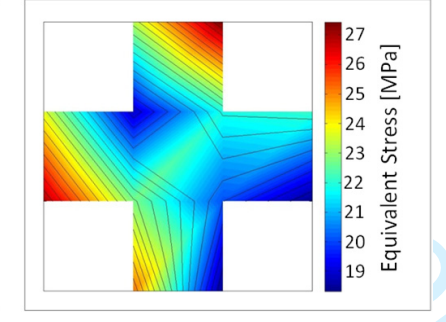

Variance
Fig. 10. Profile 4: Equivalent stress (left) and variance (right)

The mean distributions of all four cure profiles show a maximum stress at the centre of the chip and reduced stress towards the edge. This corresponds roughly to the previously described model of a uniformly loaded beam, supported at its ends [21].

The range of stress values measured for all four profiles is presented in Fig. 11. Microwave Profile 1 shows stress values ranging between $29 \mathrm{MPa}$ and $40.5 \mathrm{MPa}$. The measurements of Microwave Profile 2 result in values between $26 \mathrm{MPa}$ and $39 \mathrm{MPa}$. Microwave Profile 3 shows significantly higher values of between $42 \mathrm{MPa}$ and $58.3 \mathrm{MPa}$. The conventionally cured reference profile yields values between $54 \mathrm{MPa}$ and $80.5 \mathrm{MPa}$. The stresses occurring in the microwave curing profiles are therefore significantly lower compared to the stresses in the conventionally cured samples. While the stresses in the packages cured with Profile 1 and Profile 2 are in the same range, Profile 3 shows a significantly higher stress compared to the first two profiles. A possible explanation for the higher residual stresses in Profile 3 might lie in a higher degree of cure compared to other microwave profiles, which is likely to result in higher residual stresses. This hypothesis is principally in line with previous work on cure kinetics modelling [26]. The results of the conventional cured packages are in a comparable range as values obtained for transfer moulding of QFN packages [22].

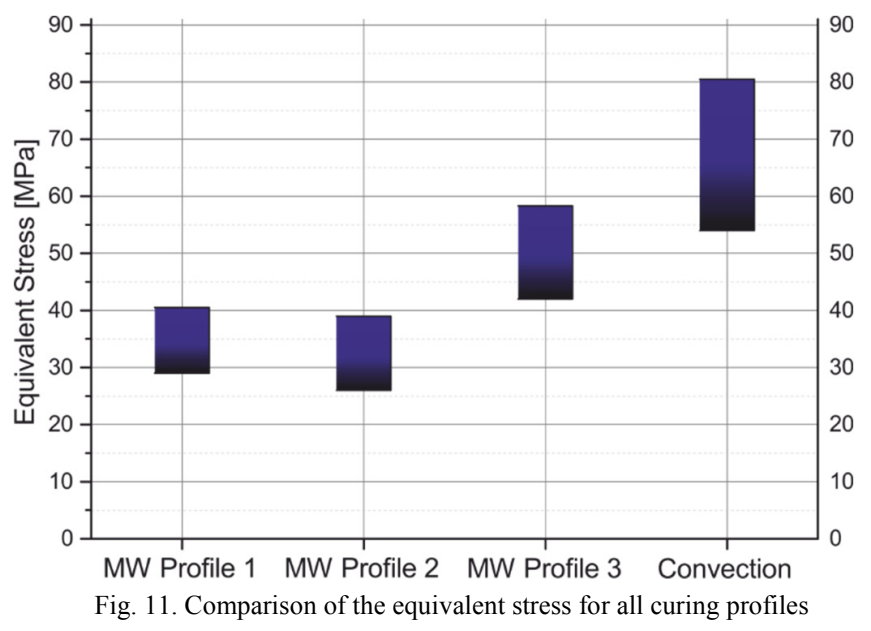

The variances in the stress values are large for both the microwave-cured and oven-cured samples. Potential sources for this variance include: (1) die and open package dimensions, (2) position and orientation of die after bonding, (3) amount of conductive adhesive used for die bonding, (4) amount of encapsulant, (5) residual stresses in the open package, (6) stress induced by the test socket and (7) defects in the package such as delamination. Since the variances for microwave and conventionally cured packages are in the same range and a high number of plausible causes exist, such stresses can likely be attributed to the assembly process and the test socket.

The significantly lower stresses within the microwave-cured packages correlate with the improved reliability determined in the TCT and HAST tests. It can therefore be concluded that the proposed method of microwave curing induced less stress than convection oven curing. In order to get a better understanding of the underlying mechanisms, further investigations beyond the scope of this paper are indicated. In a possible next step the results could be evaluated using multiphysics models such as those proposed by Tilford et al. [27]. By these models the influence of the curing mode onto the residual stress and warpage could be studied in detail. Furthermore the parameters of the curing process could be optimized towards different applications.

\section{CONCLUSIONS}

Open QFN packages with a representative IC have been subjected to a cavity-fill encapsulation process. The encapsulant was cured with three different microwave profiles using a novel microwave curing system based on an open-ended microwave oven, which allows rapid curing of encapsulant. Additionally, a control group was prepared which was conventionally cured in a convection oven.

QFNs with microwave-cured encapsulant were demonstrated to exhibit higher life-time during temperature cycling testing. Some profiles show statistically significant improvement. An additional set of experiments was performed with a stress measurement chip in a similar package with the same process profiles. The experiment revealed much lower residual stresses for the microwave processed packages, which can be attributed to the volumetric cure and is a possible explanation for the improved life-time. 
From the experiments described in this paper a number of conclusions can be drawn:

- Microwave curing allows the processing of encapsulants in polymer packages without apparent detrimental effects to the IC and its packaging.

- Microwave curing of encapsulants are shown to increase the lifetime of the package compared to their conventionally cured counterparts.

- Microwave curing allows the manufacturing of packages with significantly reduced residual stresses.

The experiments described in this paper have been performed with relatively small sample sizes. Due to the magnitude of effect, it was still however possible to identify statistically significant improvements by the application of certain microwave profiles. These curing profiles will be a primary subject for further investigation with larger sample sizes. As the design parameters and process parameters both have an influence onto the residual stresses [28], experimental investigation should be furthermore extended to other package types and designs. Also tests with active components and components mounted on PCBs should be performed.

In summary, this article provides confidence that rapid microwave curing with the proposed system is possible without apparent detrimental effects to the package dies and can potentially provide strong beneficial effects such as reduction of residual stresses and increased package life-time.

\section{ACKNOWLEDGMENTS}

Furthermore the authors would like to acknowledge the support by M. Bazu from IMT Bucharest for the support in performing the climate chamber tests. This work was supported in part by the European Union Framework 7 programme, contract number 218350, through the project entitled "FAMOBS".

\section{REFERENCES}

[1] Sejin Han and K. K. Wang, "Analysis of the flow of encapsulant during underfill encapsulation of flip-chips," IEEE Trans. Compon. Packag Manuf. Technol. Part B, vol. 20, no. 4, pp. 424-433, Nov. 1997.

[2] L. Liu, S. Yi, L. S. Ong, and K. S. Chian, "Finite element analysis for microwave cure of underfill in flip chip packaging," Thin Solid Films, vol. 462, pp. 436-445, 2004.

[3] J. B. Wei, Z. Fathi, Binghua Pan, Chih Kai Nah, and Su Liang Chan, "Use of microwave technology for rapid cure of chip-on-board glob top encapsulants," in Electronics Packaging Technology Conference, 2000. (EPTC 2000). Proceedings of 3rd, Singapore, 2000, pp. 181-185.

[4] S.K. Pavuluri, M. Ferenets, G. Goussetis, M.P.Y. Desmulliez, T. Tilford, R. Adamietz, G. Muller, F. Eicher, and C. Bailey, "Experimental investigation of open-ended microwave oven assisted encapsulation process", in Electronic Systems Technology Conference 2010 (ESTC 2010), Proceedings of $3^{\text {rd }}$, Berlin 2010, pp. 1-6.,

[5] K. Johnston, S. K. Pavuluri, M. T. Leonard, M. P. Y. Desmulliez, and V. Arrighi, "Microwave and thermal curing of an epoxy resin for microelectronic applications," Thermochim. Acta, vol. 616, pp. 100109, Sep. 2015.

[6] S. K. Pavuluri, M. Ferenets, G. Goussetis, M.P.Y. Desmulliez, T. Tilford, R. Adamietz, G. Mueller, F. Eicher and C. Bailey, "Encapsulation of Microelectronic Components Using Open-Ended Microwave Oven," IEEE Trans. Compon. Packag. Manuf. Technol., vol. 2, no. 5, pp. 799-806, May 2012.
[7] K.I. Sinclair, M.P.Y. Desmulliez, A.J. Sangster, "A novel RF-curing technology for microelectronics and optoelectronics packaging", Proc. of IEEE Electronics Systems Integration Technology Conference (ESTC), vol.2, pp. 1149-1157, September 2006.

[8] What is LabVIEW? - National Instruments. [Online]. Available: http://www.ni.com/labview. [Accessed: 26-Mar-2018].

[9] JEDEC Solid State Technology Association. JESD22-A104D, "Temperature Cycling", March, 2009.

[10] JEDEC Solid State Technology Association. JESD22-A110D, "Highly Accelerated Temperature and Humidity Stress Test (HAST)", November, 2010.

[11] "Weibull - Reliability Life Data Analysis," ReliaSoft. [Online]. Available: https://www.reliasoft.com/Weibull/. [Accessed: 26-Mar2018].

[12] D. R. Cox and D. Oakes, Analysis of survival data. Boca Raton: Chapman and Hall/CRC, 1998.

[13] J. Cohen, "A power primer," Tutorials in Quantitative Methods for Psychology, vol. 3, no. 2, pp. 79-79, Jan. 2007.

[14] T. Tilford, K. I. Sinclair, G. Goussetis, C. Bailey, M. P. Y. Desmulliez, A. K. Parrott, and A. J. Sangster, "Comparison of encapsulant curing with convection and microwave systems," 2008 33rd IEEE/CPMT International Electronics Manufacturing Technology Conference (IEMT), 2008.

[15] R. Jaeger, J. Suhling, R. Ramani, A. Bradley, and J. Xu, "CMOS stress sensors on [100] silicon," IEEE Journal of Solid-State Circuits, vol. 35, no. 1 , pp. $85-95,2000$

[16] J. Schwizer, W. H. Song, M. Mayer, O. Brand, and H. Baltes, "Packaging test chip for flip-chip and wire bonding process characterization," TRANSDUCERS 03. 12th International Conference on Solid-State Sensors, Actuators and Microsystems. Digest of Technical Papers (Cat. No.03TH8664).

[17] Y. Chen, R. Jaeger, and J. Suhling, "Multiplexed CMOS Sensor Arrays for Die Stress Mapping," 2006 Proceedings of the 32nd European Solid-State Circuits Conference, 2006.

[18] S. Hirsch, S. Doerner, P. Hauptmann, and B. Schmidt, “A New Test Device for Characterization of Mechanical Stress Caused by Packaging Processes," Journal of Physics: Conference Series, vol. 34, pp. 39-44, Jan. 2006.

[19] H. Kittel, Abschlussbericht zum Verbundvorhaben iForceSens: Entwicklung eines integrierten Stressmesssystems zur Quantifizierung der 3D-Verformung von Sensorbauelementen in Abhängigkeit des Verpackungsprozesses ; Laufzeit des Vorhabens: 01.01.200530.06.2008. Abstatt, 2008.

[20] S. Majcherek, T. Leneke, and S. Hirsch, "A silicon test chip for the thermomechanical analysis of MEMS packagings," Microsystem Technologies, vol. 15, no. 1, pp. 191-200, 2008.

[21] P. Gieschke and O. Paul, "CMOS-integrated Sensor chip for in-plane and out-of-plane shear stress," Procedia Engineering, vol. 5, pp. 13641367, 2010.

[22] T. Schreier-Alt, G. Chmiel, F. Ansorge, and K.-D. Lang, "Piezoresistive stress sensor for inline monitoring during assembly and packaging of QFN," 2013 IEEE 63rd Electronic Components and Technology Conference, 2013.

[23] J. Suhling and R. Jaeger, "Silicon piezoresistive stress sensors and their application in electronic packaging," IEEE Sensors Journal, vol. 1, no. 1 ,pp. 14-30, 2001.

[24] W. D. Callister and D. G. Rethwisch, Fundamentals of materials science and engineering: an integrated approach. Singapore: Wiley, 2016.

[25] N. E. Dowling, Mechanical Behavior of Materials Engineering Methods for Deformation, Fracture, and Fatigue. Englewood Cliffs, NJ: Prentice Hall, 2013.

[26] J. E. Morris, T. Tilford, C. Bailey, K. I. Sinclair, and M. P. Desmulliez, "Polymer cure modeling for microelectronics applications," $200932^{\text {nd }}$ International Spring Seminar on Electronics Technology, 2009.

[27] T. Tilford, K. Sinclair, C. Bailey, M. Desmulliez, G. Goussettis, A. Parrott, and A. Sangster, "Multiphysics simulation of microwave curing in micro-electronics packaging applications," Soldering \& Surface Mount Technology, vol. 19, no. 3, pp. 26-33, Mar. 2007.

[28] D. Yang, L. Ernst, K. Jansen, G. Zhang, J. Janssen, and H. Bressers, "Process-induced Warpage in HVQFN Package: Effect of Design Parameters and Processing Conditions," Polytronic 2005 - 5th International Conference on Polymers and Adhesives in Microelectronics and Photonics, 2005. 
Raphael Adamietz was born in Wetzlar, Germany in 1982. He received his Diploma degree in mechanical engineering from the Karlsruhe Institute of Technology (KIT) in 2008. He received a $\mathrm{PhD}$ degree from the University of Stuttgart, Germany in 2018. Since 2009 he works for the FraunhoferInstitute Manufacturing Engineering and Automation (IPA) as Research Associate and from 2012 as project manager. His research interests include processes and machinery for micro-assembly and electronic packaging, adhesive bonding, microwave curing, novel automation concepts, combination of additive manufacturing and micro-assembly technologies and evolvable assembly systems.

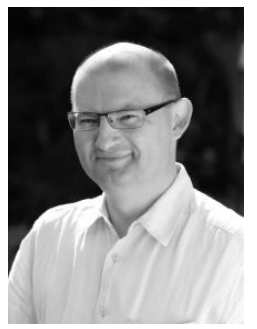

Group.

He has authored over 450 papers and holds 9 patents in the fields of optoelectronics, microelectronics, and MEMS packaging and novel manufacturing techniques.

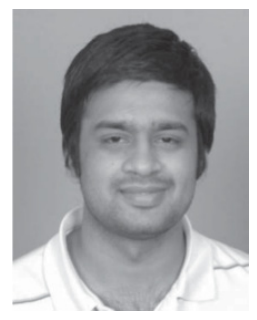

Sumanth Kumar Pavuluri received the B.Tech. degree in electronics and communications engineering from Jawaharlal Nehru Technological University, Hyderabad, India, the M.Sc. degree in microsystems engineering from Heriot-Watt University, Edinburgh, U.K., and the Ph.D. degree from Heriot-Watt University, in 2004, 2005, and 2011, respectively. He is currently a Post-Doctoral Research Associate with Heriot-Watt University, working on the frequency agile microwave oven bonding system project. His current research interests include modeling, fabrication and testing of radio frequencymicroelectromechanical systems devices, micromachined antennas, waveguide cavity ovens, microwave sensing, curing, and integrated circuit packaging.

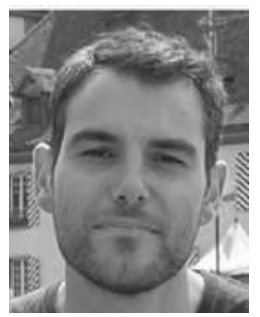

Tim Tilford obtained a Bachelor's degree in Aeronautical Engineering from Queen Mary College, University of London, United Kingdom, in 1998 and subsequently a Master's Degree in Computational Fluid Dynamics from the University of Greenwich, United Kingdom, in 1999. He obtained a PhD in Computational
Mechanics from the University of Greenwich in 2013. He has been a Research Fellow and subsequently a Senior Lecturer at the University of Greenwich since 2002 . His primary research interests are in numerical analysis of multiphysics/multi-scale problems and high performance parallel computing. Dr. Tilford is a Fellow of the Institute of Maths and its Applications, a Chartered Mathematician and a Chartered Scientist

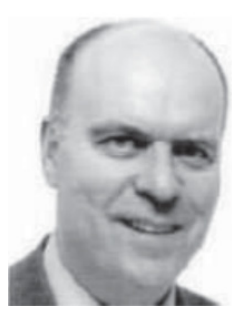

Chris Bailey (M'92-SM'06) received the $\mathrm{Ph} . \mathrm{D}$. degree in computational modeling and the M.B.A. degree in technology management in 1988 and 1996, respectively. $\mathrm{He}$ is a Professor of computational mechanics and reliability with the University of Greenwich, London, U.K, and the Director of the Computational Mechanics and Reliability Group. He has published over 200 papers on design and simulation of micro/nanotechnology-based processes and products and has worked on many U.K. and European Union projects. His current research interests include multiphysics/scale modeling of micro-nanosystems, predictive reliability, and prognostics. Dr. Bailey is a member of the Board of Governers of the IEEE Components, Packaging and Manufacturing Technology Society and a Committee Member of the International Microelectronics and Packaging Society, U.K.

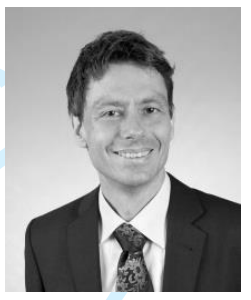

Thomas Schreier-Alt received his $\mathrm{PhD}$ in Engineering at Technical University Berlin, Germany. He is a professor of polymer engineering at University RavensburgWeingarten, Germany since 2015. His research interests include additive manufacturing, smart materials and bionic engineering. Prof. Schreier-Alt is a member of IMAPS Deutschland.

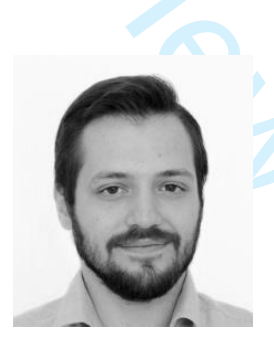

Jens Warmuth received the B.Sc. degree in engineering physics and the M.Sc. degree in micro- and nanotechnology from the Munich University of Applied Sciences, Munich, Germany, in 2013 and 2015, respectively. Between 2013 and 2016 he worked at the Fraunhofer-Institute for Reliability and Microintegration (IZM) and from 2016 onwards as a Research Associate at the Fraunhofer-Institute for Integrated Circuits (IIS), Division Engineering of Adaptive Systems (EAS) in Dresden, Germany. His research interests include reliability of electronic devices and systems, especially coupling of physical simulations with statistical field data and sensors for online damage detection, as well as influence of mechanical stress on IC functionality and performance. 


\section{Weibull Plots of Temperature Cycling Test Results}

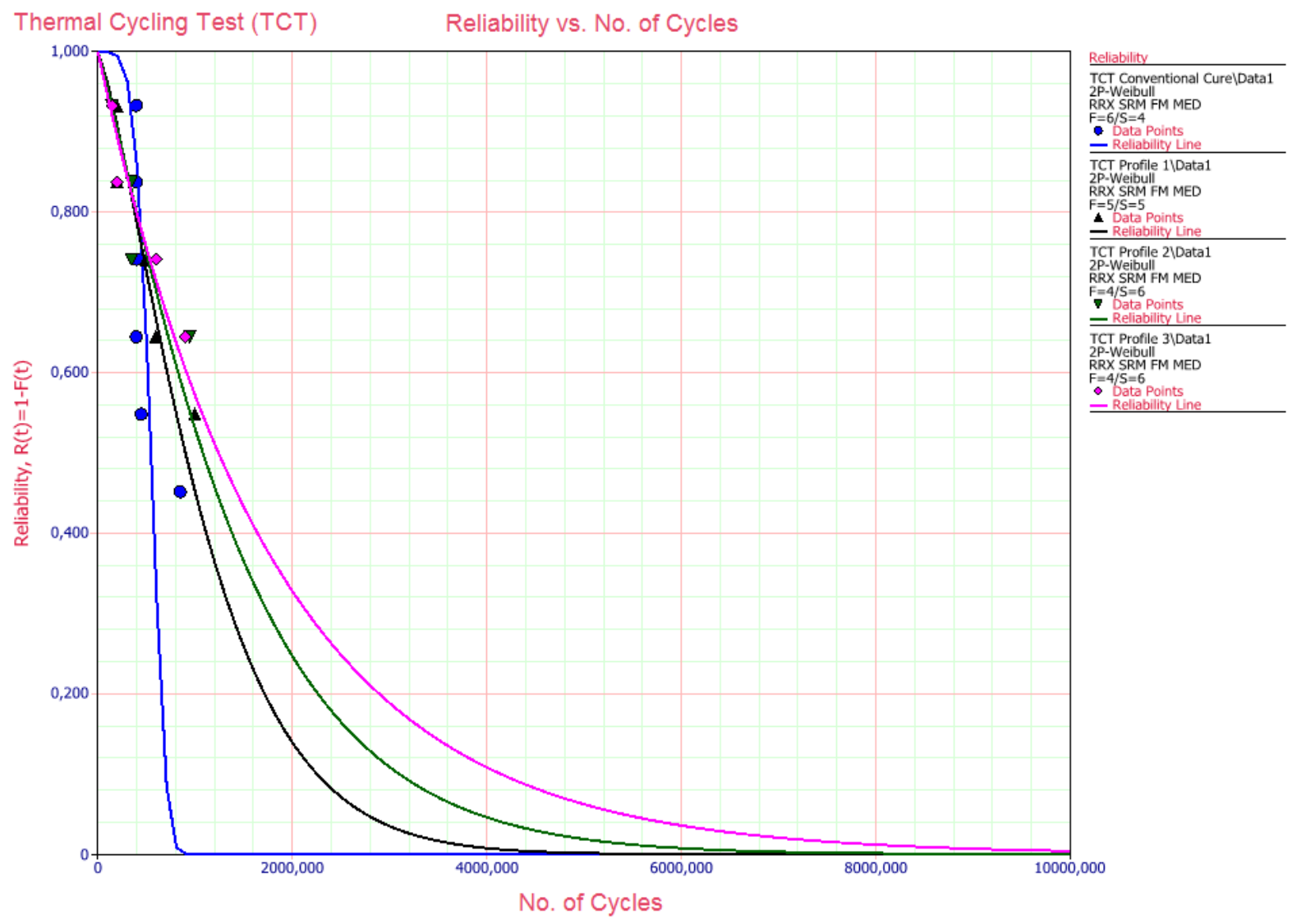

Fig. A1. Plots of Weibull Functions for Temperature Cycling Test 


\section{Weibull Plots of Temperature Cycling Test after HAST}

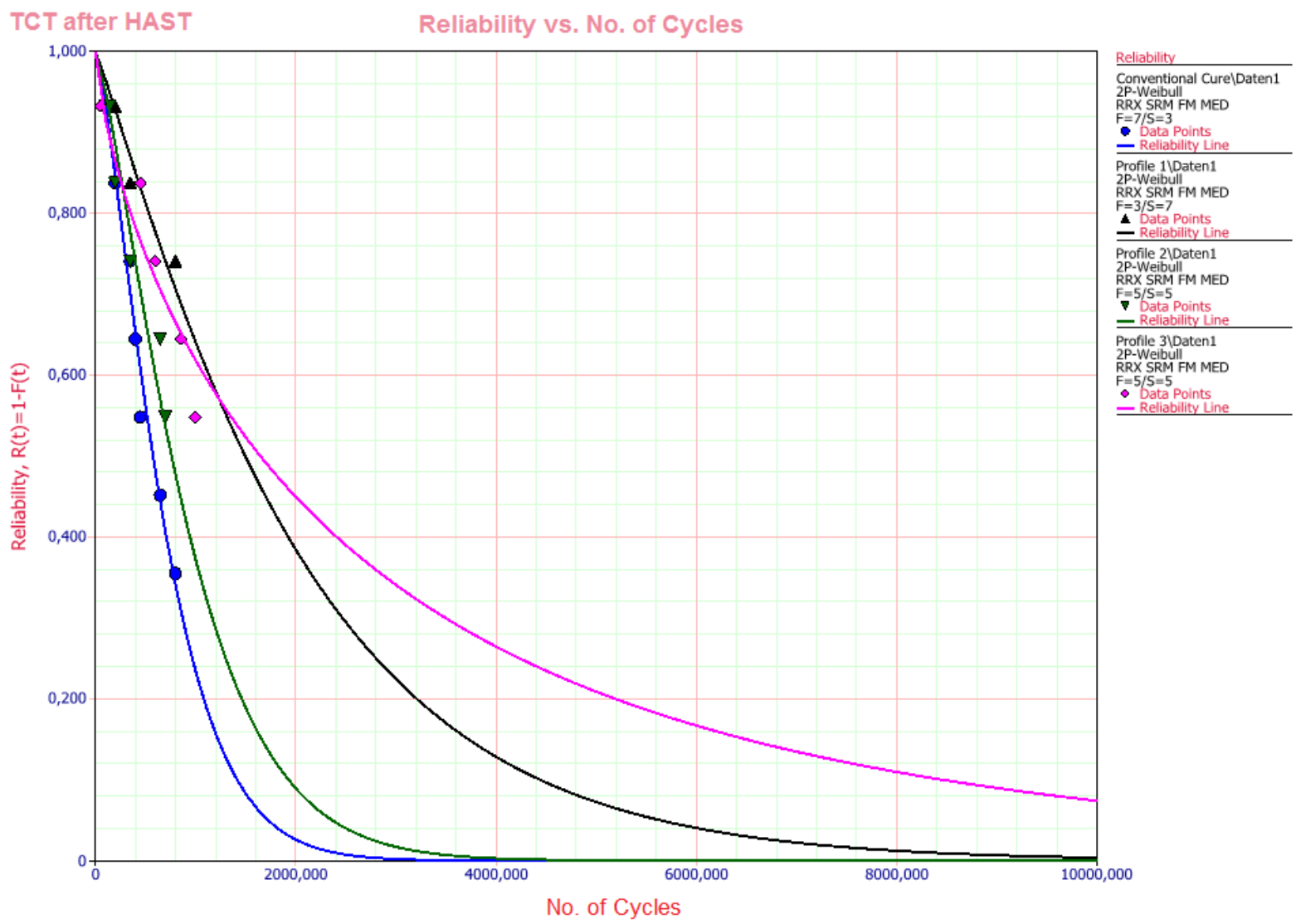

Fig. A2. Plots of Weibull Functions for Temperature Cycling Test after HAST 


\section{Stress Measurement - Microwave Profile 1}

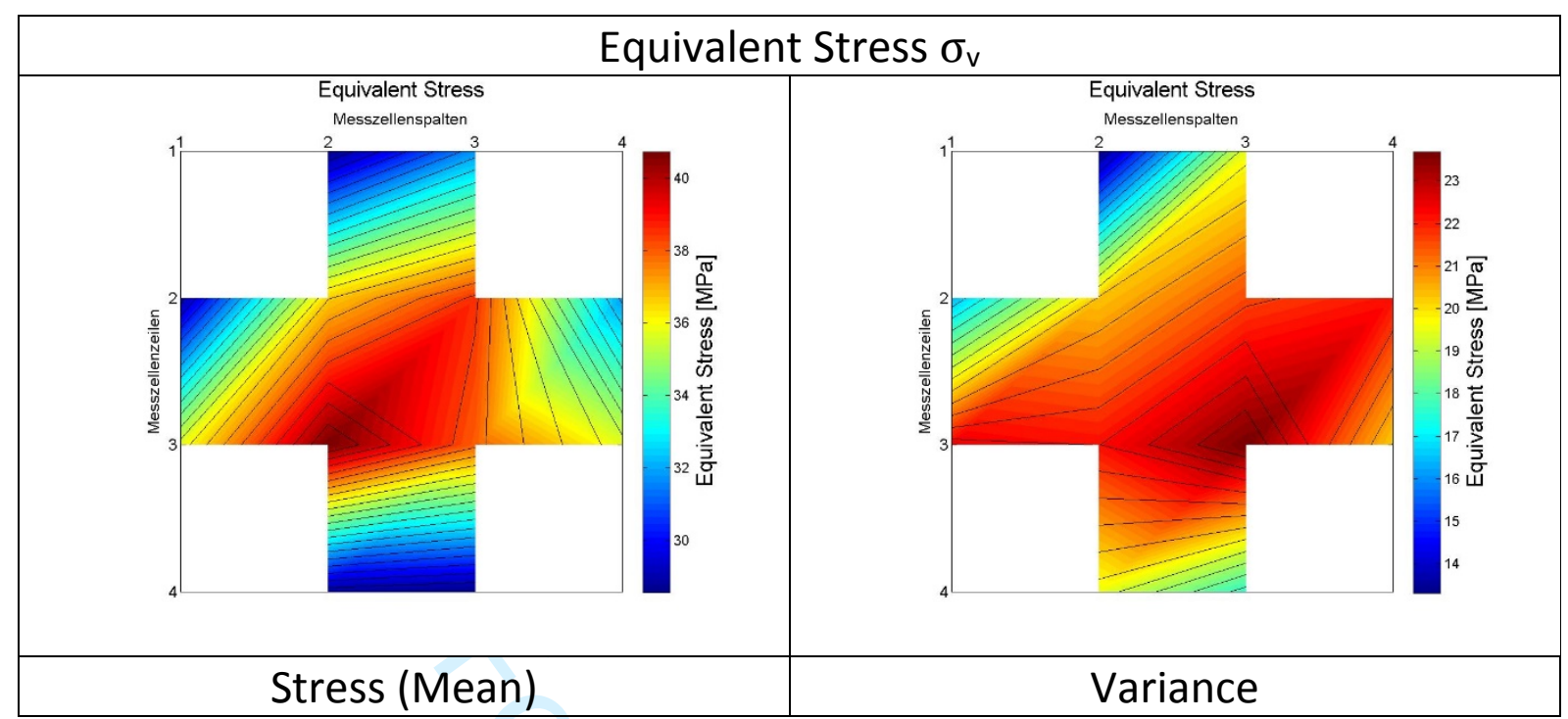

Fig. A3. Profile 1 - Equivalent Stress

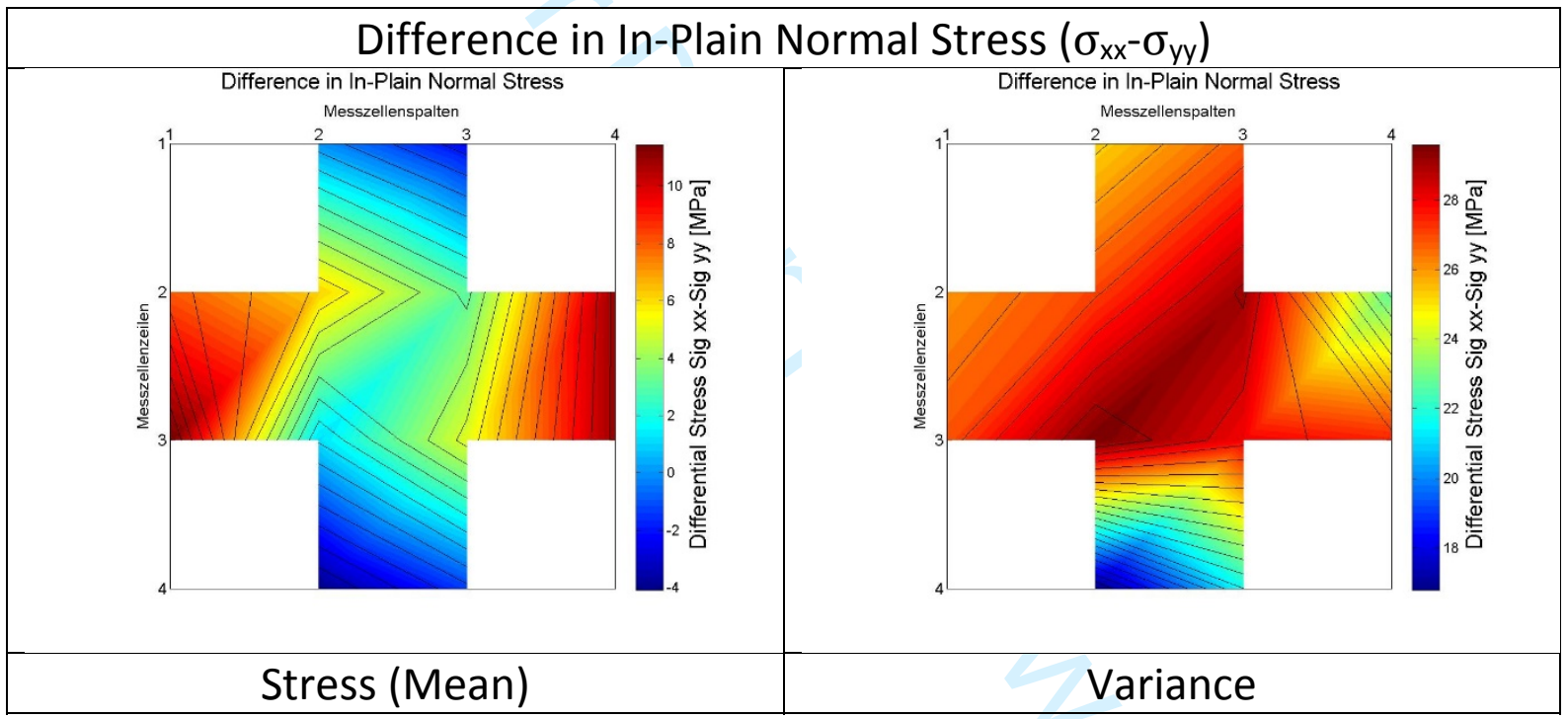

Fig. A4. Profile 1 - Difference in In-Plain Normal Stress

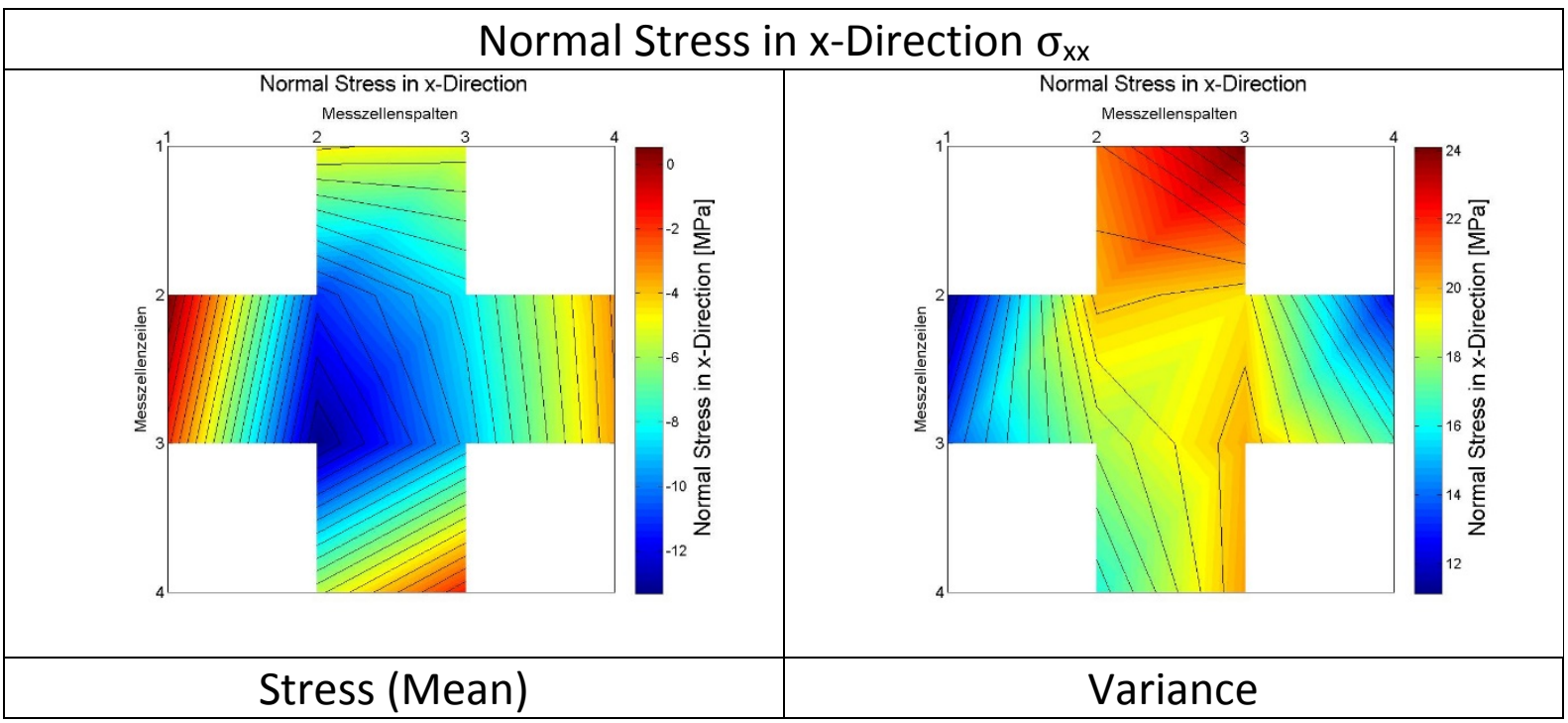

Fig. A5. Profile 1 - Normal Stress in $x$-Direction 


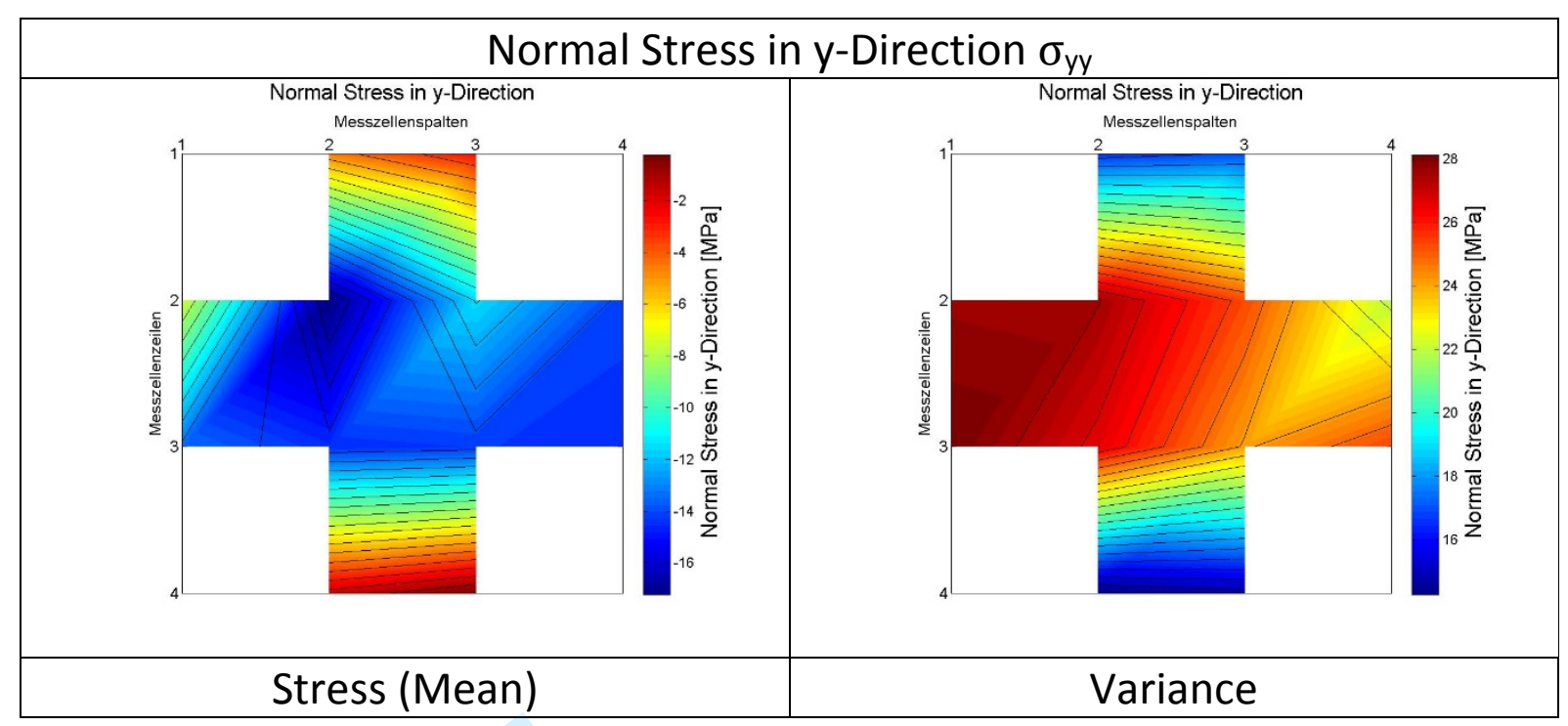

Fig. A6. Profile 1 - Normal Stress in y-Direction

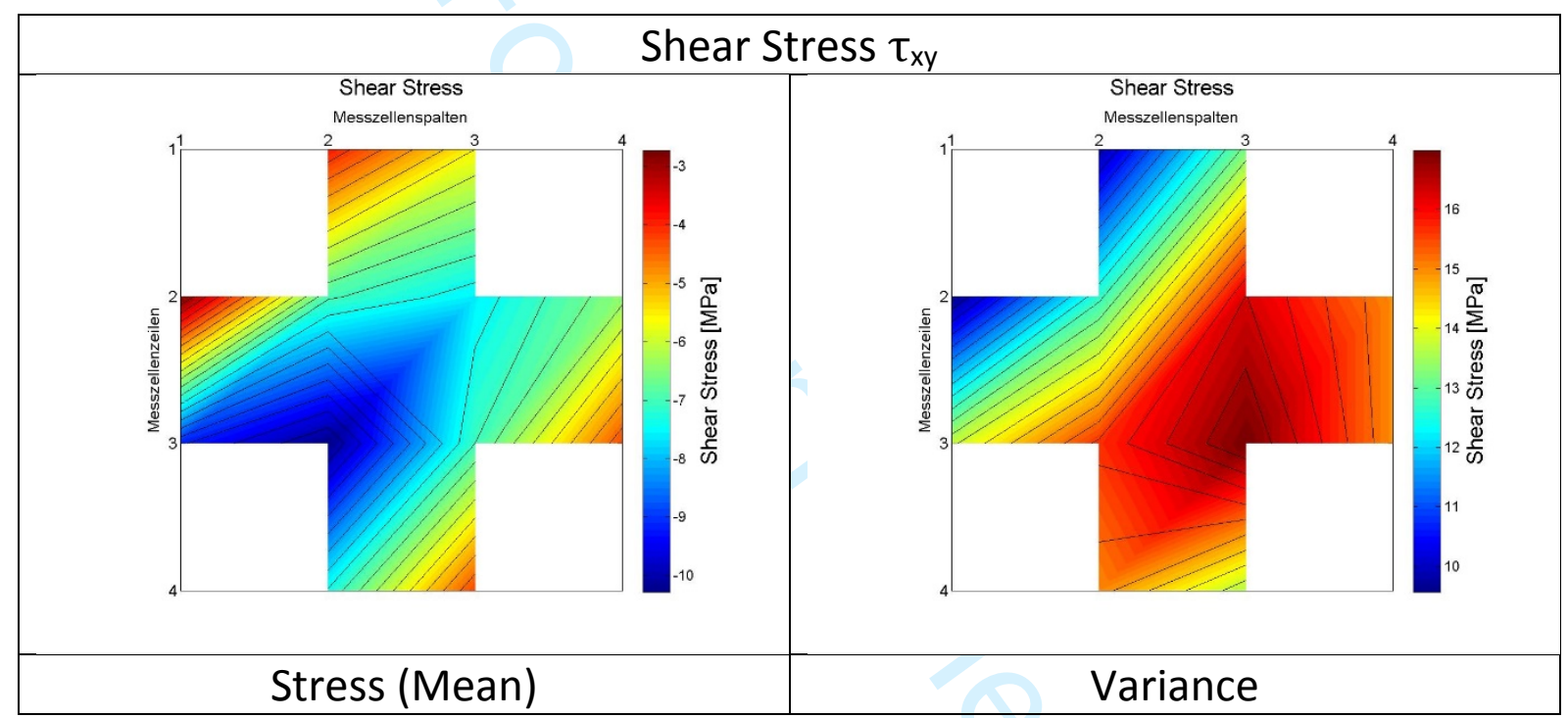

Fig. A7. Profile 1-Shear Stress 


\section{Stress Measurement - Microwave Profile 2}

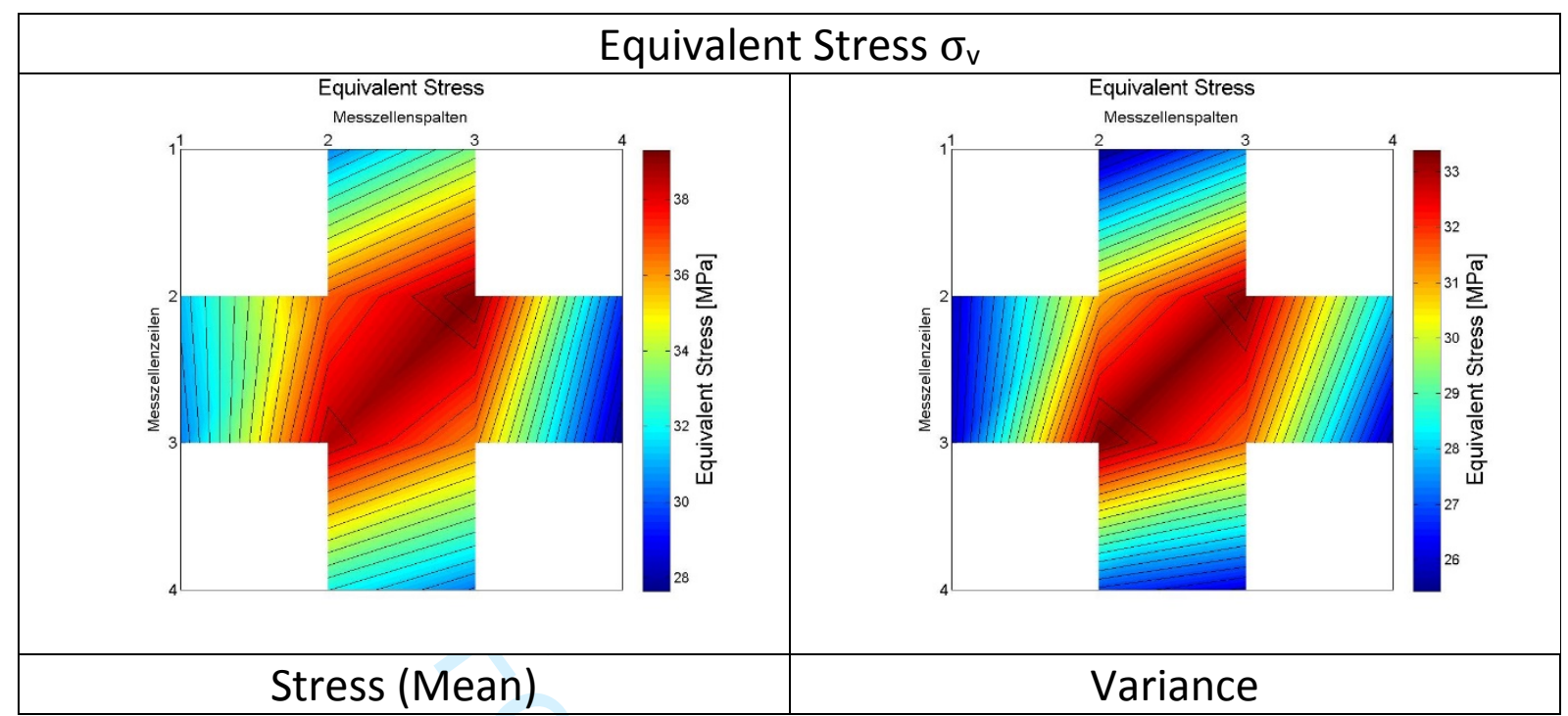

Fig. A8. Profile 2-Equivalent Stress

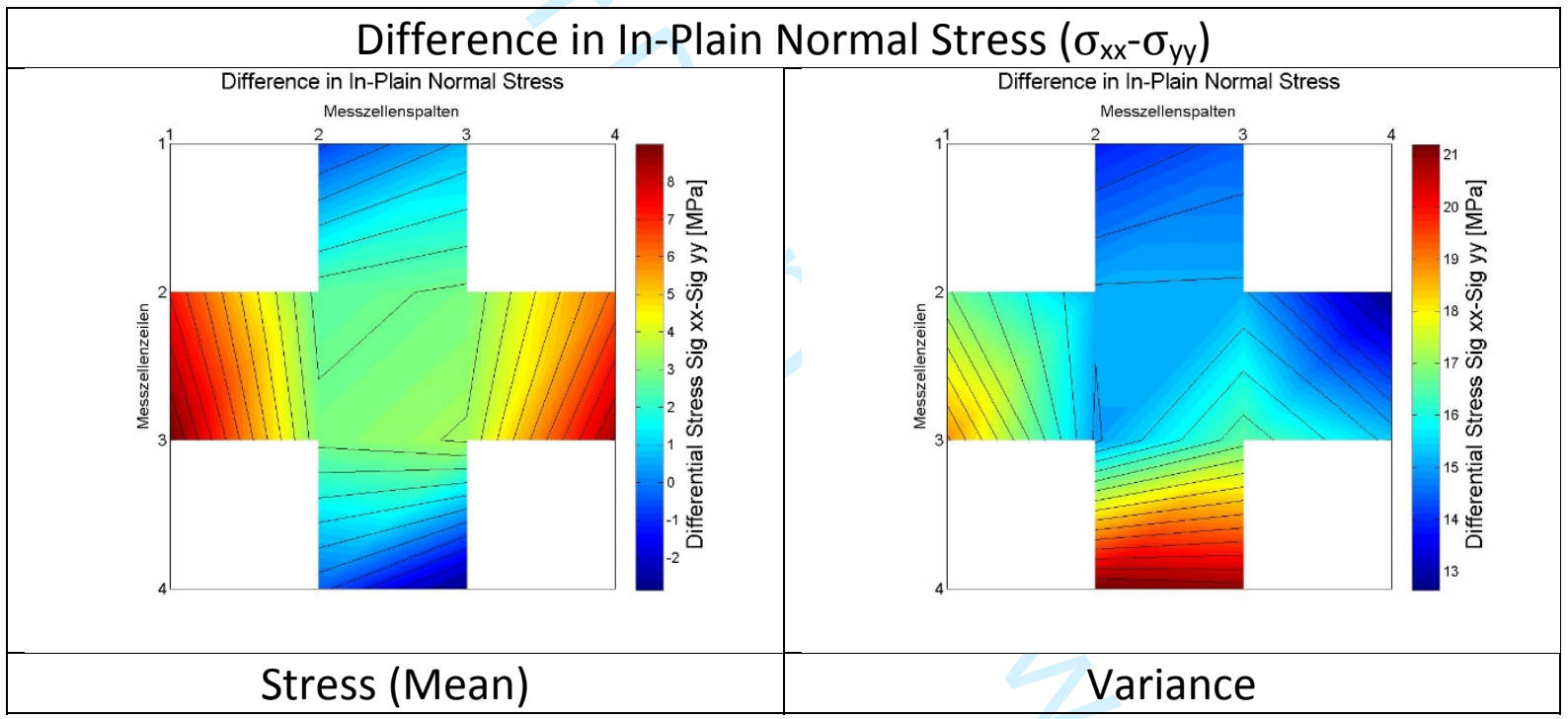

Fig. A9. Profile 2-Difference in In-Plain Normal Stress

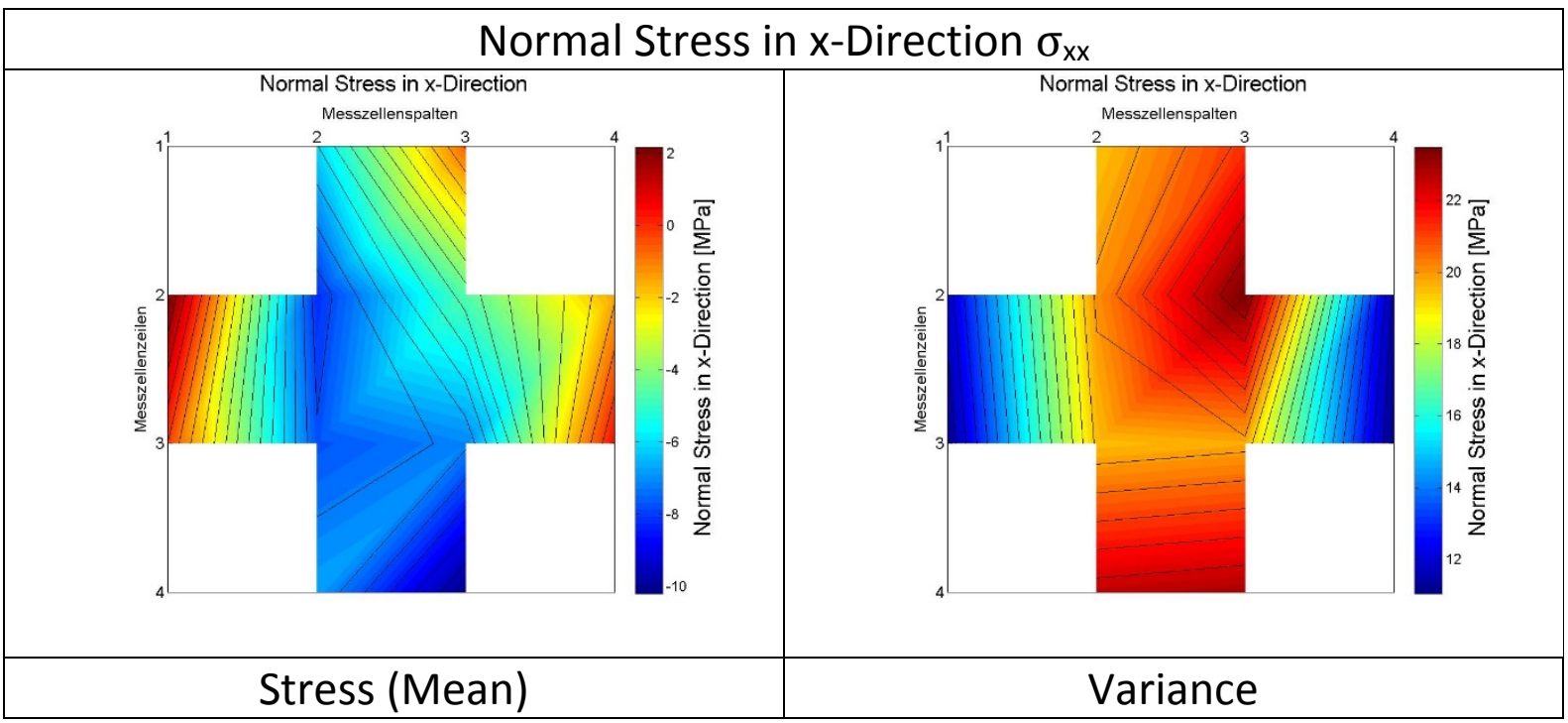

Fig. A10. Profile 2 - Normal Stress in $x$-Direction 


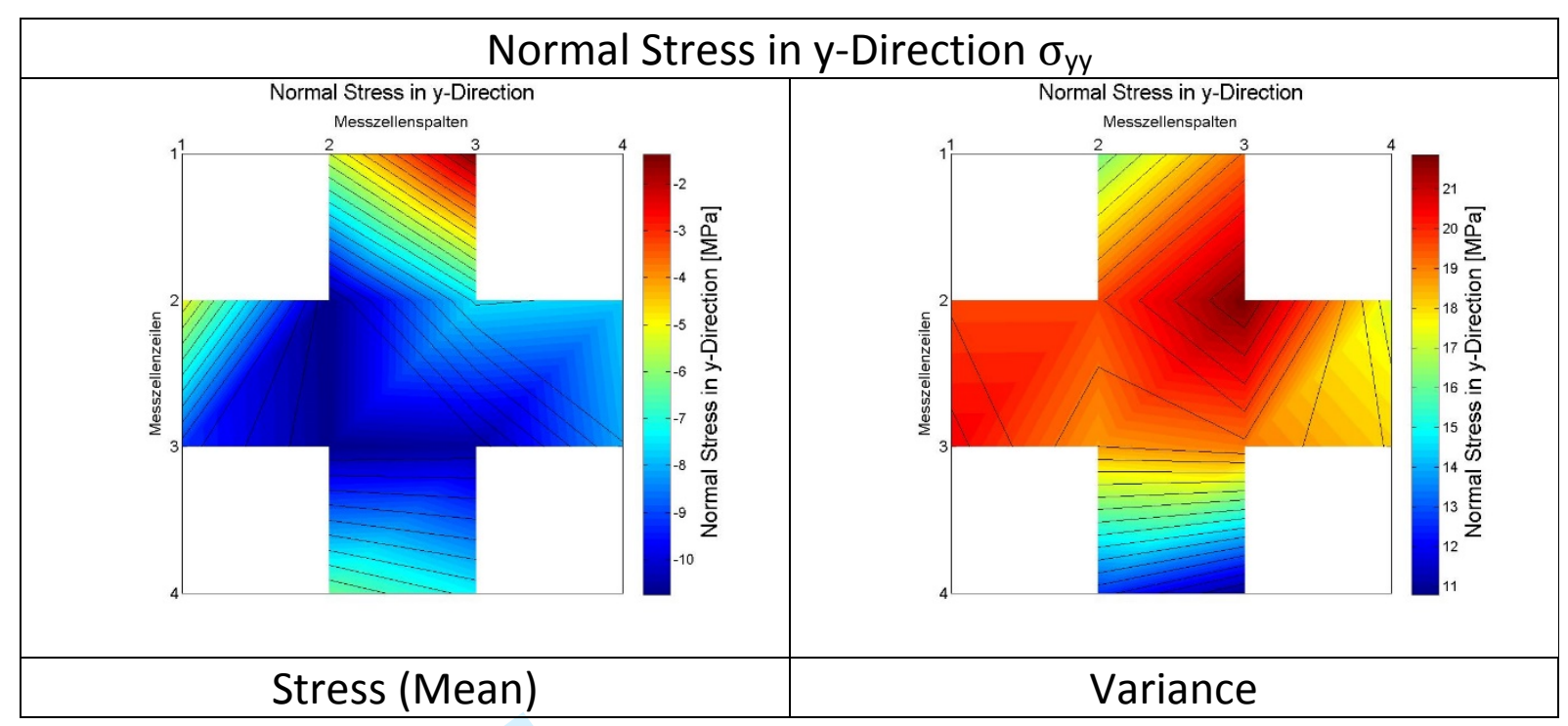

Fig. A11. Profile 2-Normal Stress in y-Direction

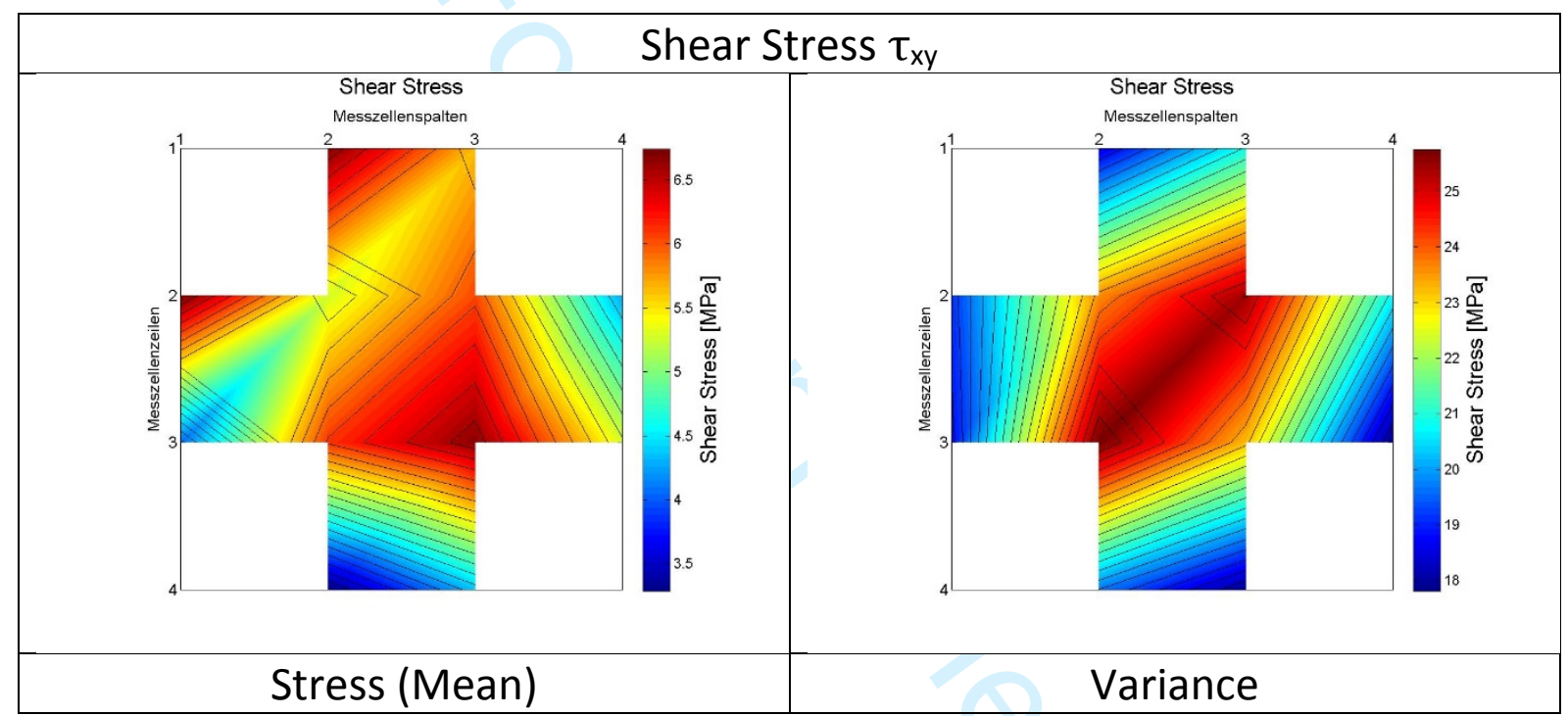

Fig. A12. Profile 2 - Shear Stress 


\section{Stress Measurement - Microwave Profile 3}

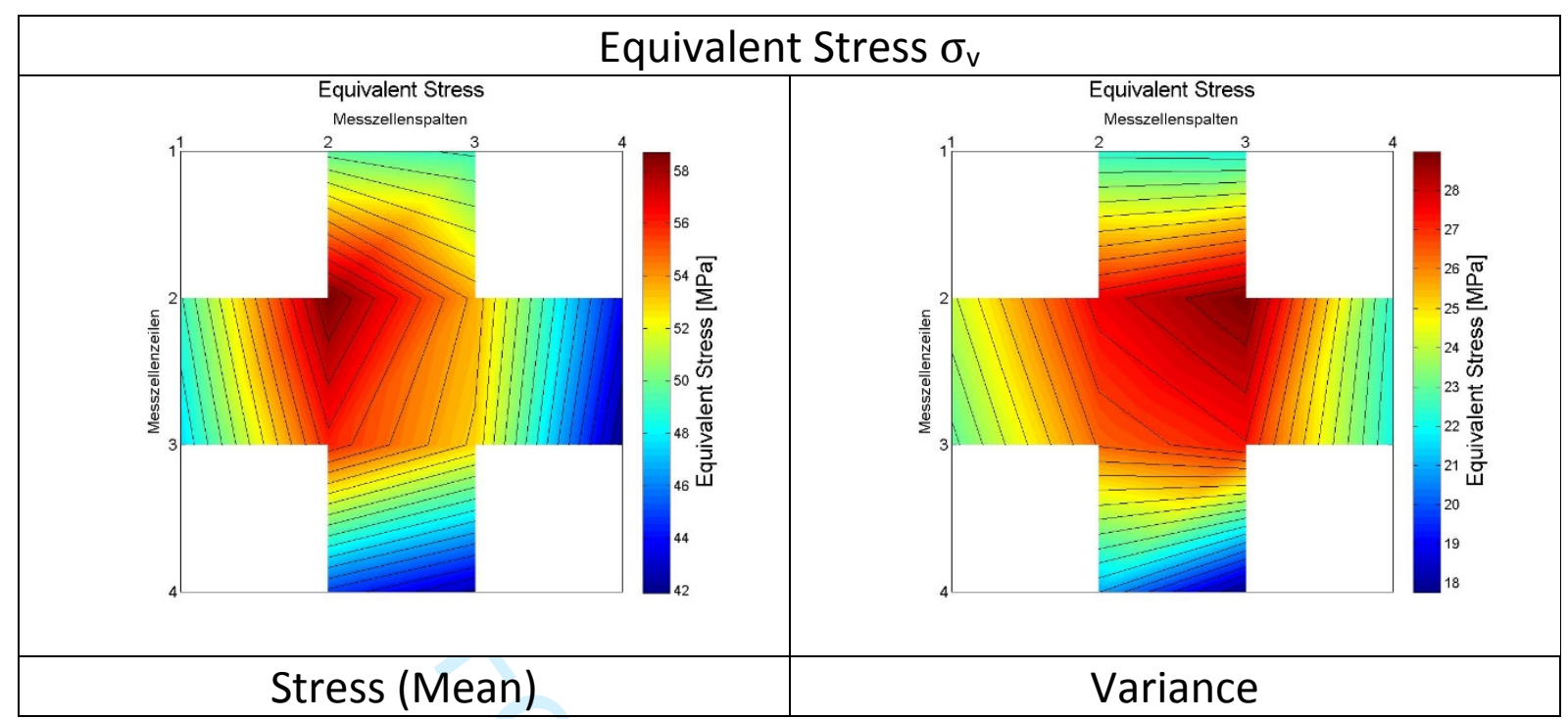

Fig. A13. Profile 3 - Equivalent Stress

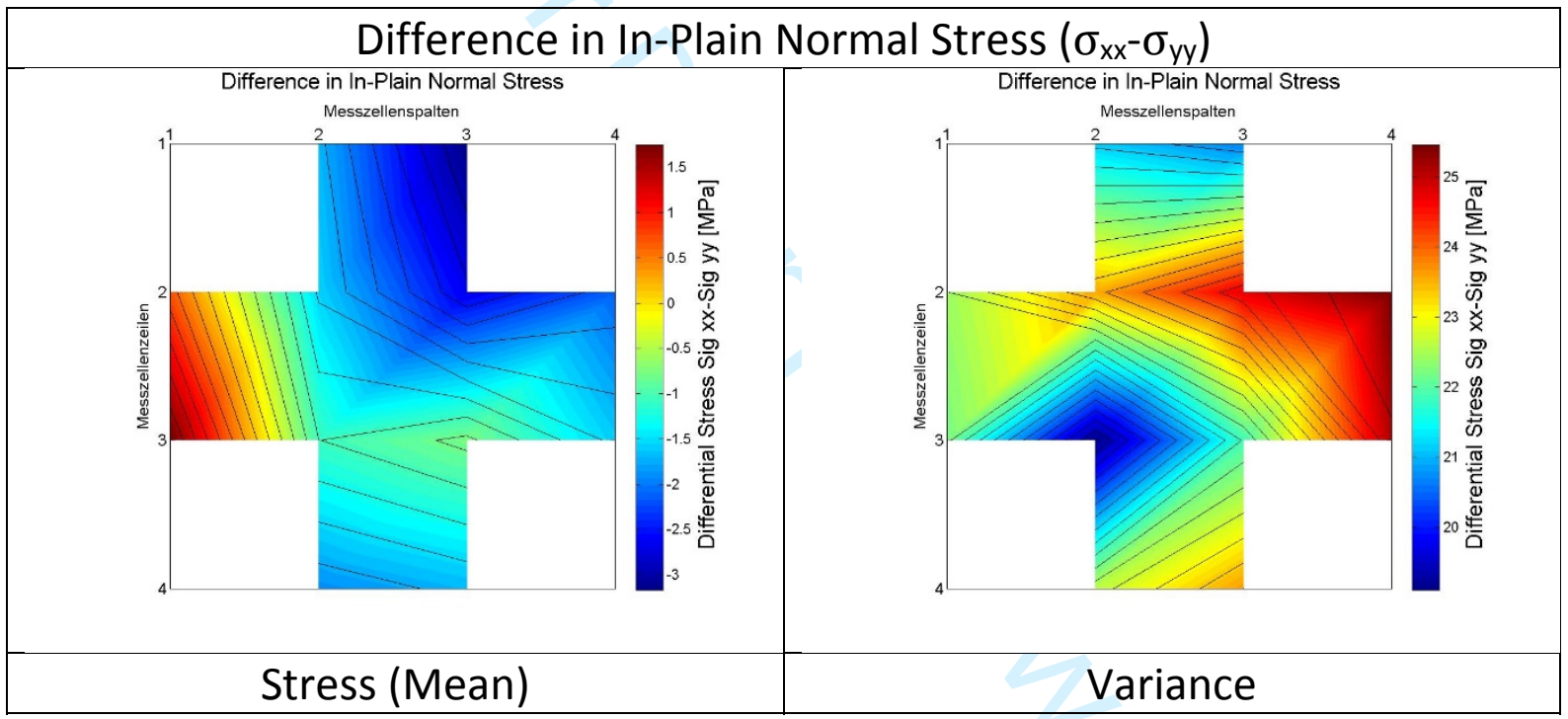

Fig. A14. Profile 3-Difference in In-Plain Normal Stress

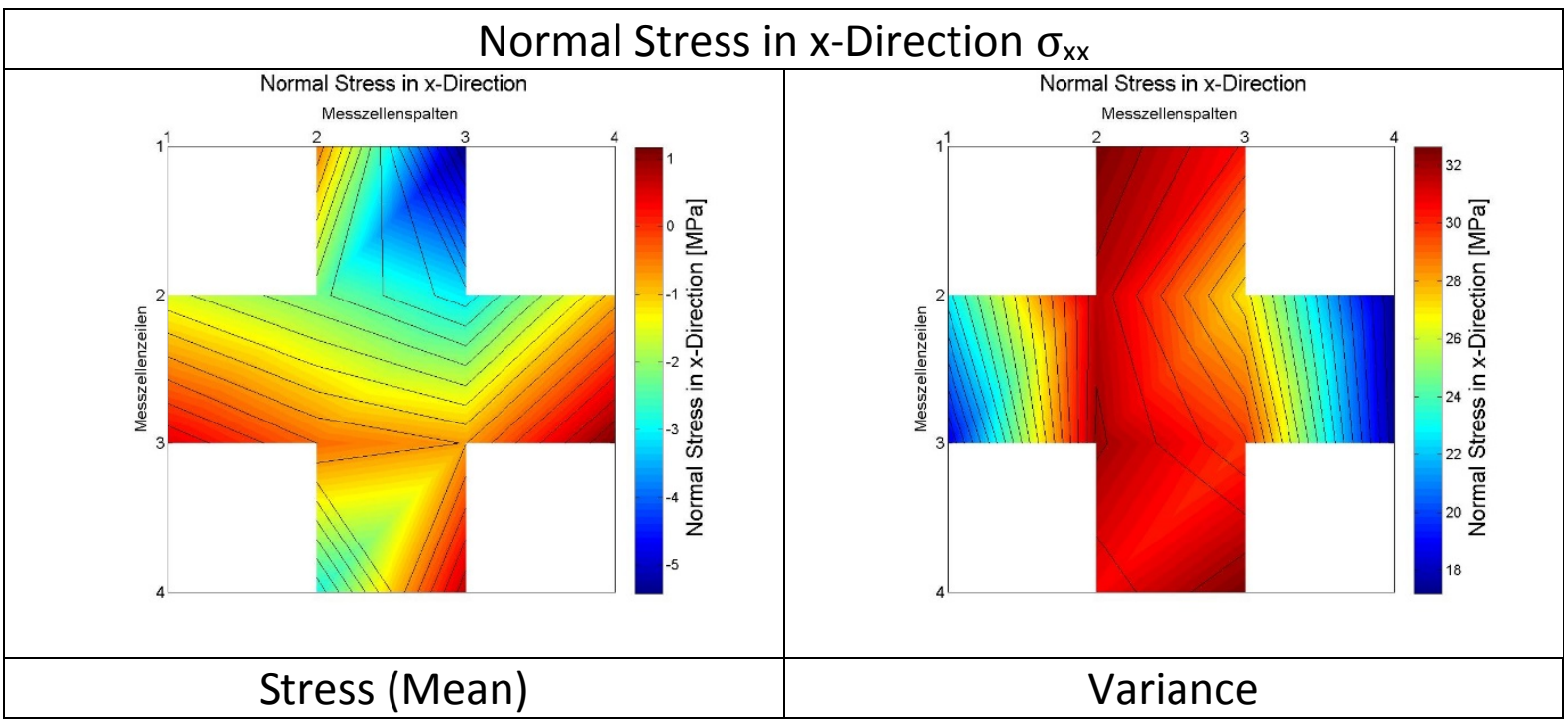

Fig. A15. Profile 3 - Normal Stress in $x$-Direction 


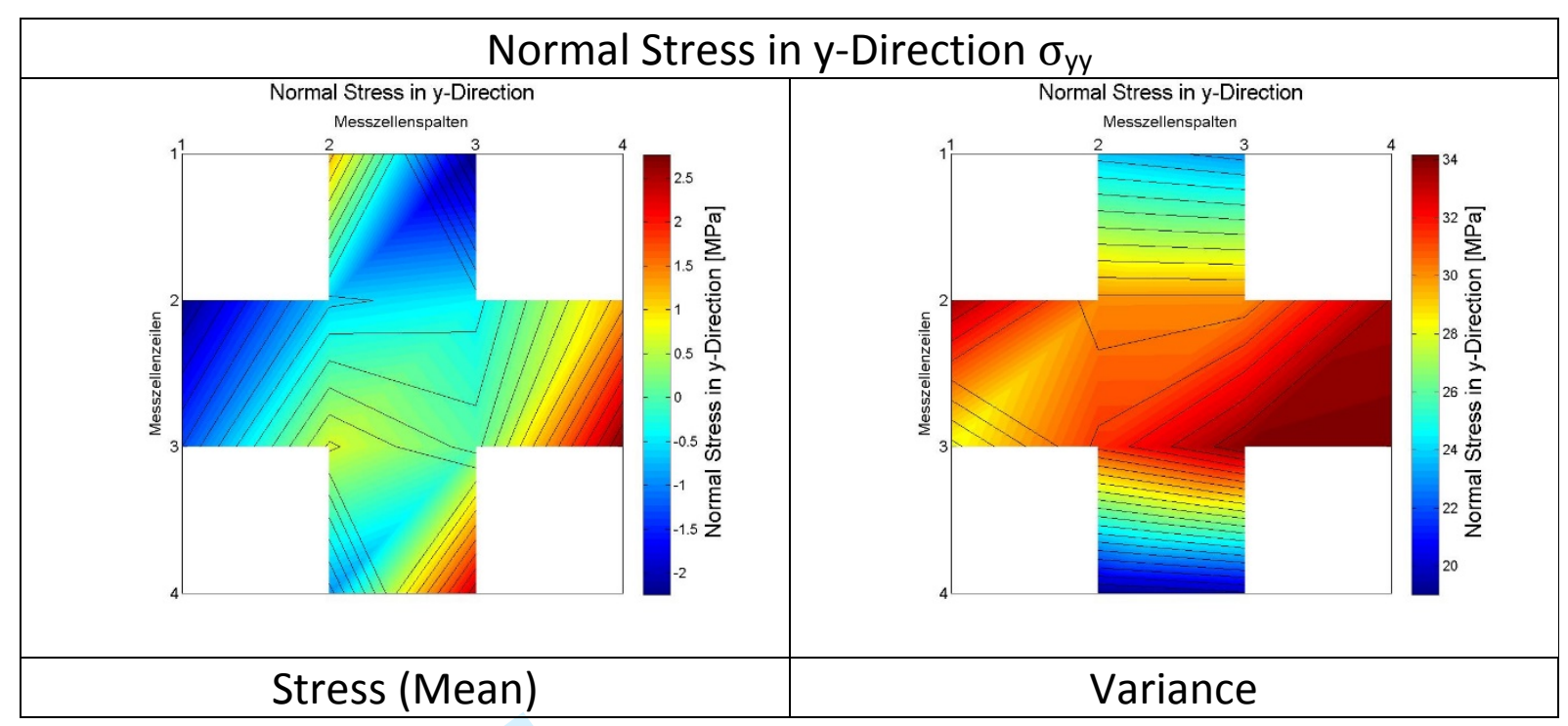

Fig. A16. Profile 3-Normal Stress in y-Direction

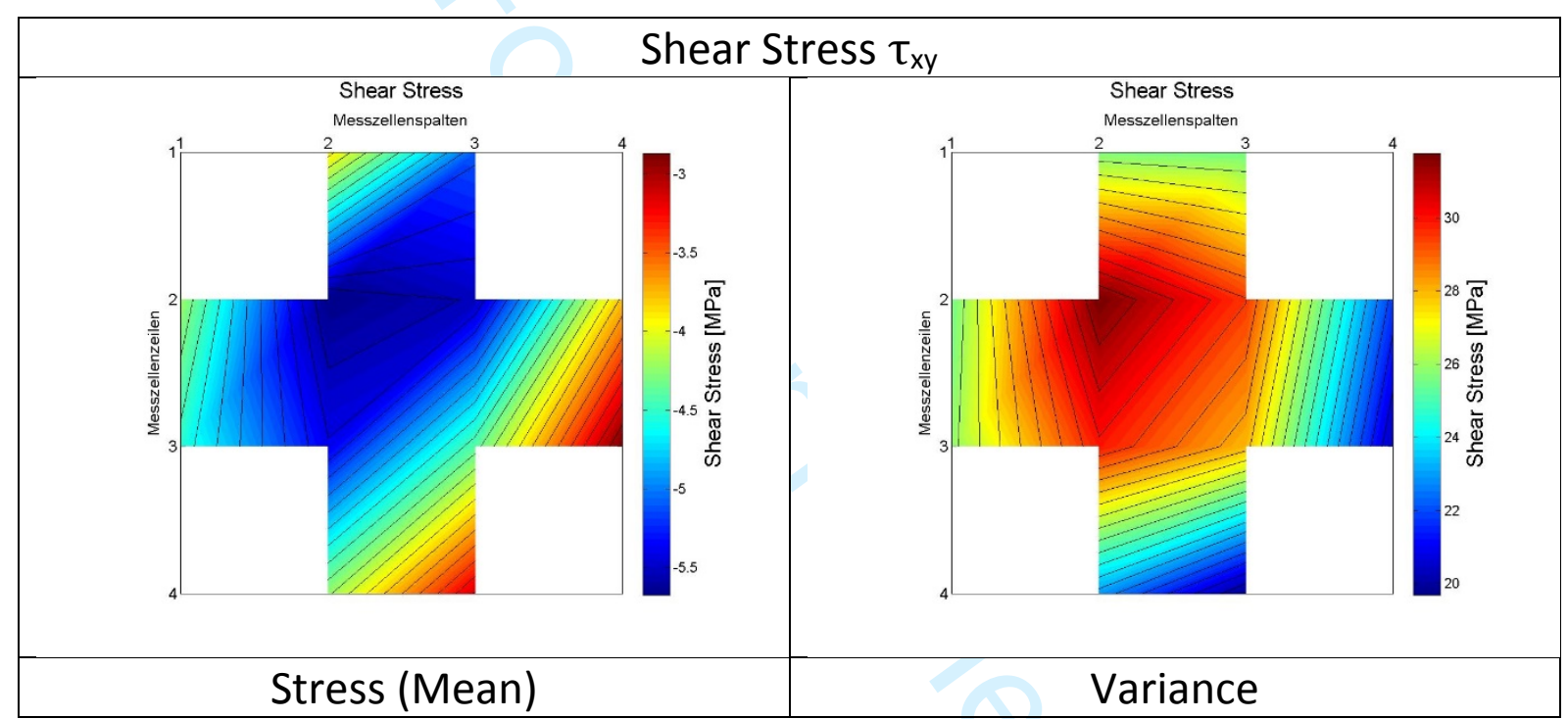

Fig. A17. Profile 3 - Shear Stress 


\section{Stress Measurement - Convection Oven}

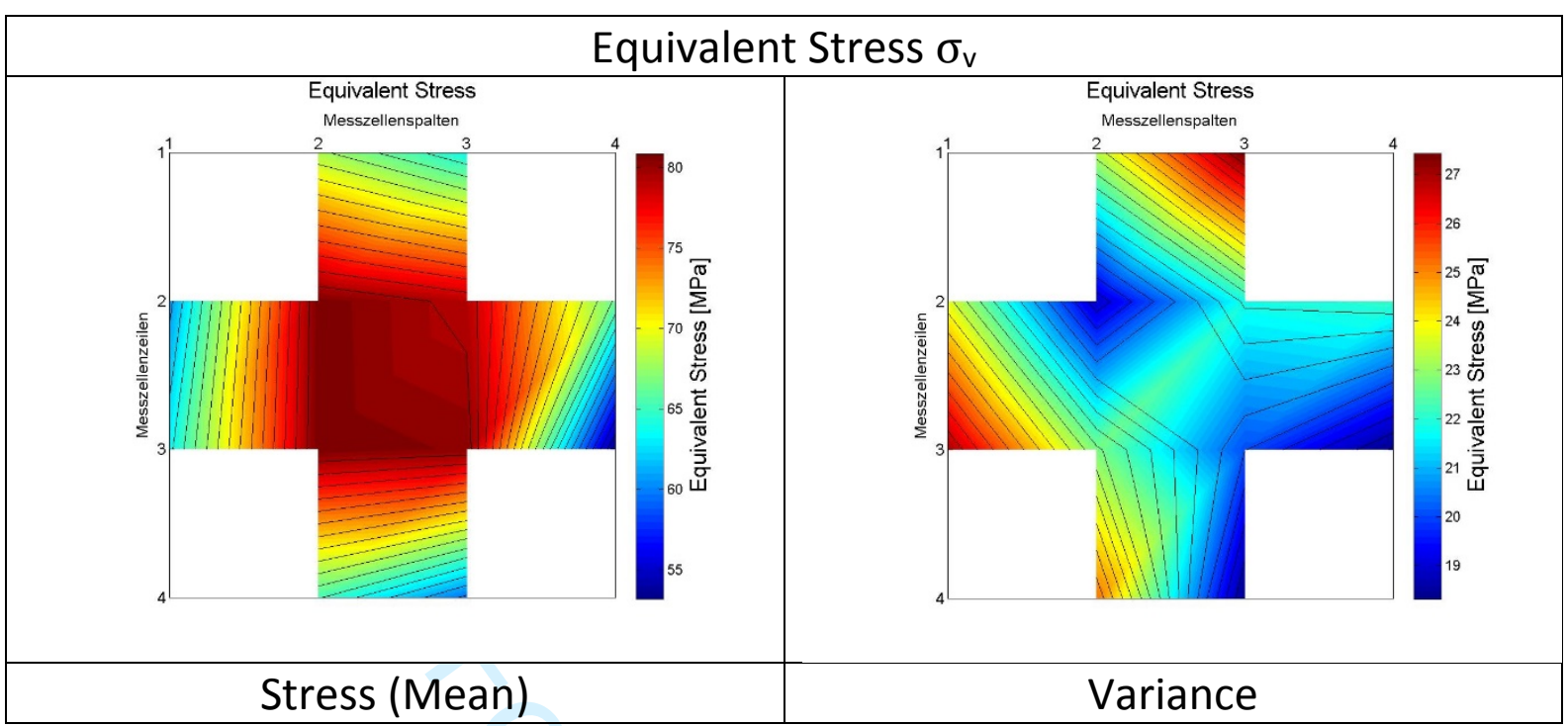

Fig. A18. Convection Oven - Equivalent Stress

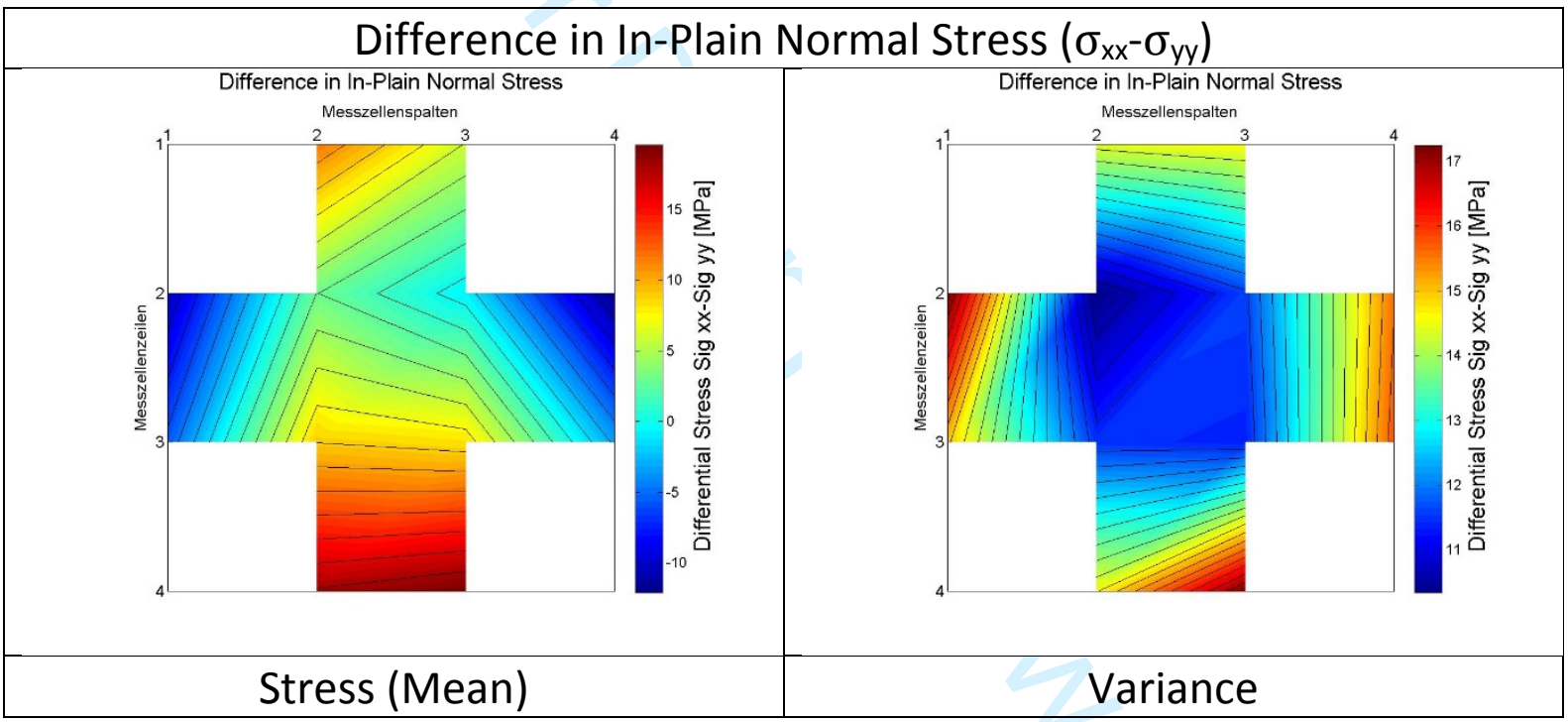

Fig. A19. Convection Oven - Difference in In-Plain Normal Stress

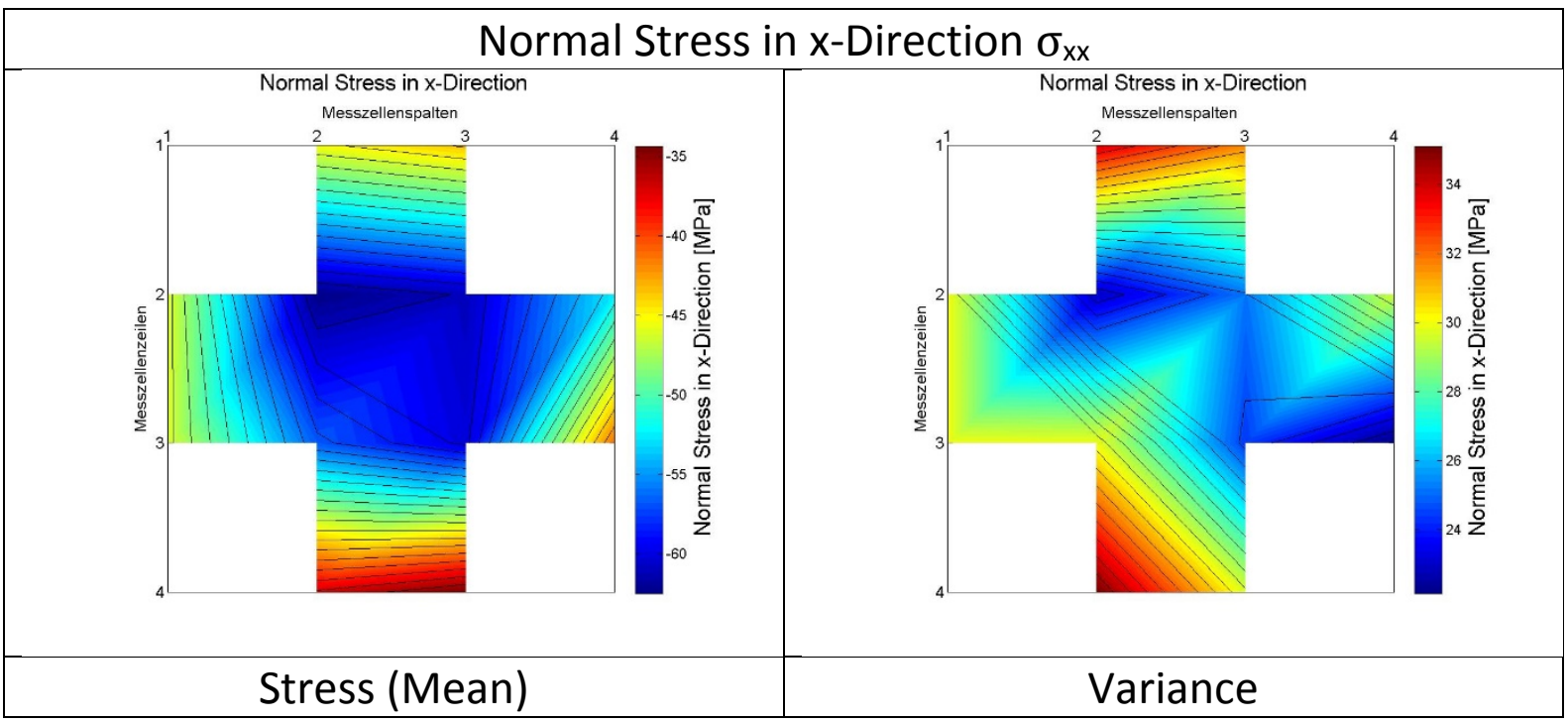

Fig. A20. Convection Oven - Normal Stress in x-Direction 


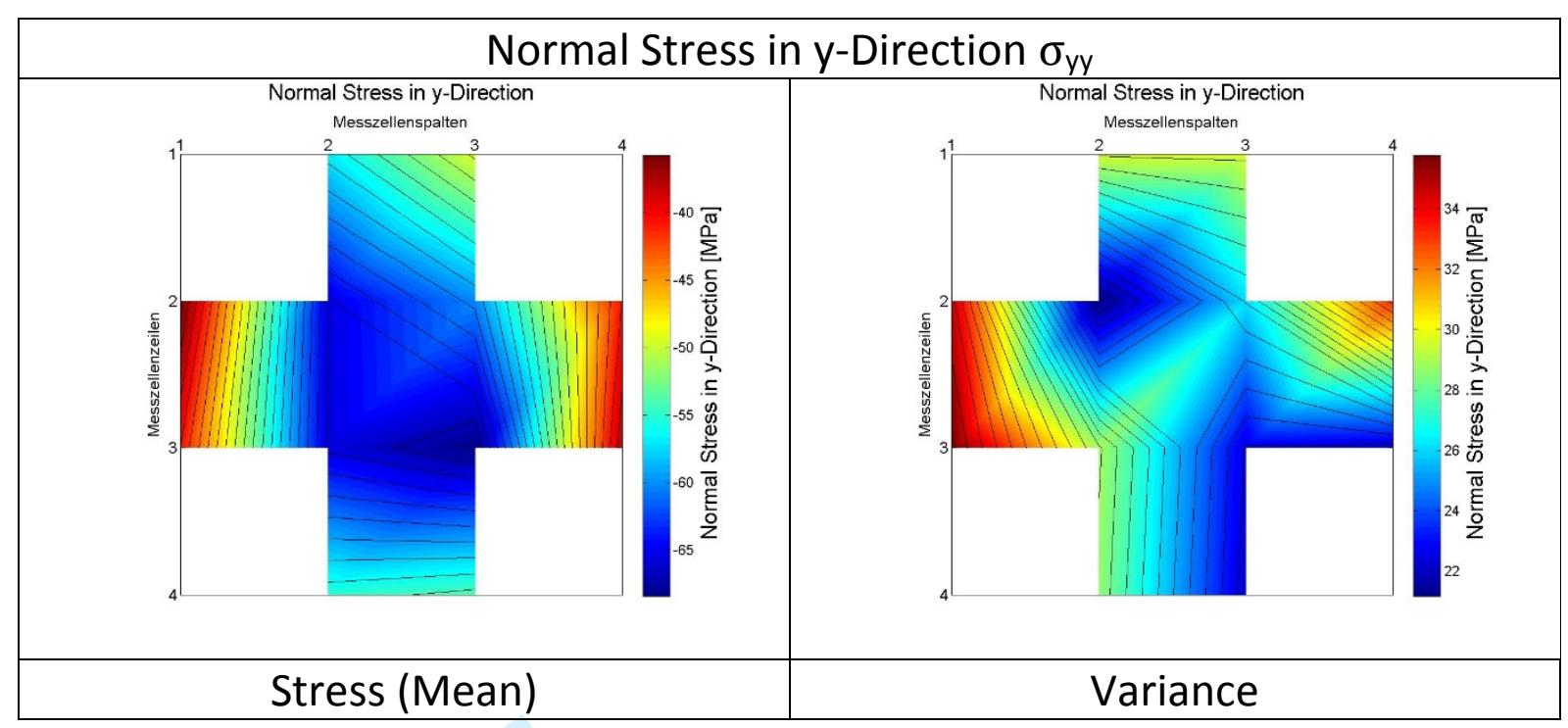

Fig. A21. Convection Oven - Normal Stress in y-Direction

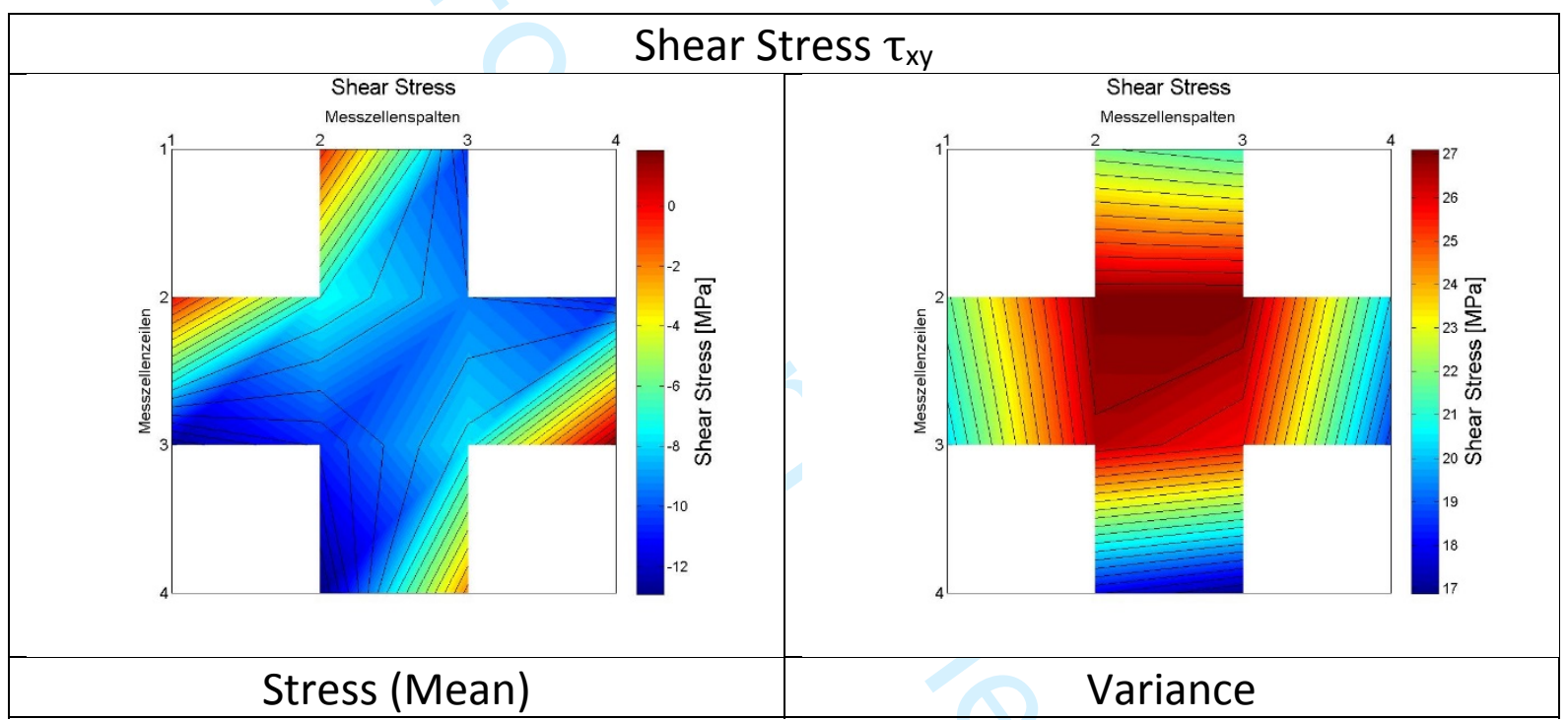

Fig. A22. Convection Oven - Shear Stress 


\section{Stress Measurement - Calculation of Equivalent Stress, Arithmetic Mean and Variance}

The equivalent stress $\sigma_{\mathrm{v}}$ is calculated by the formula for equivalent von Mises stress for general plane stress:

$$
\sigma_{v}=\sqrt{\sigma_{x x}^{2}+\sigma_{y y}^{2}-\sigma_{x x} \sigma_{y y}+3 \tau_{x y}^{2}}
$$

The pictures show the mean stress for each data point, where the arithmetic mean $\mu$ of each data point (for each profile) is calculated:

$$
\mu=\frac{1}{N} \sum_{i=1}^{N} x_{i}
$$

The variance for each data point is calculated by:

$$
\operatorname{var}(X)=\frac{1}{N-1} \sum_{i=1}^{N}\left|x_{i}-\mu\right|^{2}
$$

